\title{
Microstructure and Phase Constitution Near the Interface of Explosively Welded Aluminum/Copper Plates
}

\author{
HENRYK PAUL, LIDIA LITYŃSKA-DOBRZYŃSKA, and MARIUSZ PRAŻMOWSKI
}

\begin{abstract}
The microstructure changes and the phase constitution within the layers close to the bonding interface strongly influence the properties of bimetallic strips. In this work, the layers near the interface of explosively welded aluminum and copper plates were investigated by means of microscopic observations, mostly with the use of transmission electron microscopy (TEM) equipped with energy dispersive spectrometry (EDX). The study was focused on the identification of the intermetallic phases, the possible interdiffusion between the copper and the aluminum, and the changes in the dislocation structure of the parent plates. In macro-/mesoscale, the interfaces were outlined by a characteristic sharp transition indicating that there was no mechanical mixing between the welded metals in the solid state. In micro-/nanoscale, the layers adhering to the interface show typical deformed microstructure features, i.e., structure refinement, elongated dislocation cells, slip bands, and microtwins (in copper plate). The internal microstructure of the intermetallic inclusion is composed mostly of dendrites. The electron diffractions and TEM/EDX chemical composition measurements revealed three crystalline equilibrium phases of the $\gamma-\mathrm{Al}_{4} \mathrm{Cu}_{9}, \eta-\mathrm{AlCu}$, and $\Theta-\mathrm{Al}_{2} \mathrm{Cu}$ type (the last one was dominant). However, most of the observed phases of the general $\mathrm{Cu}_{m} \mathrm{Al}_{n}$ type (also crystalline) do not appear in the equilibrium Al-Cu phase diagram. Inside the intermetallic inclusions, no significant regularity in the phase distribution with respect to the parent sheets was observed. Therefore, it was concluded that the processes occurring in the melt determined their local chemical composition.
\end{abstract}

DOI: $10.1007 / \mathrm{s} 11661-013-1703-1$

(C) The Author(s) 2013. This article is published with open access at Springerlink.com

\section{INTRODUCTION}

IN recent years, explosive welding has emerged as a promising process for the production of (multi)layered products. The beginning of this technology dates back to the period after the Second World War. It was found that if metals could be impacted together at high velocity and oblique incidence, they would weld. This observation became the basis of a commercial process for bonding metals together, e.g. ${ }^{[1,2]}$ The cladding systems which have been addressed so far include over two hundred and sixty metal and alloy combinations, e.g. ${ }^{[3]}$ They were produced mostly as bi- or tri-layered metal compositions, in the last case, usually with a thin layer of $\mathrm{Ti}$ as the interlayer.

Explosive welding is solid-state metal joining used to create an atomic bond between two similar or dissimilar metals, especially those metal compositions that cannot be joined by any other welding or bonding techniques. A weld joint is produced by means of a high velocity impact of one metallic mass onto another, aided by a controlled detonation with an explosive charge. The

HENRYK PAUL, Professor, and LIDIA LITYŃSKADOBRZYŃSKA, Ph.D., D.Sc., are with the Institute of Metallurgy and Materials Science, 25 Reymonta St., Krakow, Poland. Contact e-mail: h.paul@imim.pl MARIUSZ PRAŻMOWSKI, Ph.D., is with the Faculty of Mechanics, Opole University of Technology, 5 Mikołajczyka St., Opole, Poland.

Manuscript submitted February 29, 2012.

Article published online March 20, 2013 process uses the explosive charge to propel a metal flyer plate toward a fixed metal base plate (Figure 1) and can be divided into three basic stages: the detonation of the explosive charge, the deformation and acceleration of the flyer plate, and the collision between the plates. ${ }^{[1-3]}$ Following the explosion, the flyer plate collapses onto the base plate and a high velocity jet is formed between the two metal plates (Figures 1(a) and (b)). Contrary to the classical methods of deformation bonding, e.g., accumulative roll-bonding or cladding by rolling, the oxide films are swept away from the interface by the jet, and the metal surfaces are cleaned. At the collision point, the perfectly clean surfaces are brought together under very high pressure. The high velocity oblique collision will "produce" high temperature and high shear strain near the collision point in a very short time. This causes local melting of the bonded metals simultaneously with the local plastic deformation. The very short time of the heat influence, due to the high thermal conductivity of the metals, leads to high cooling rates and thus, in the solidification process, the melted metals are "transformed" to brittle intermetallics of different compounds, e.g..$^{[-16]}$

Since the process occurs at a high pressure and at high cooling rates, the solidification conditions are far from equilibrium, and the occurrence of metastable phases* is

\footnotetext{
*i.e., the phases not observed in the equilibrium phase diagram.
} 


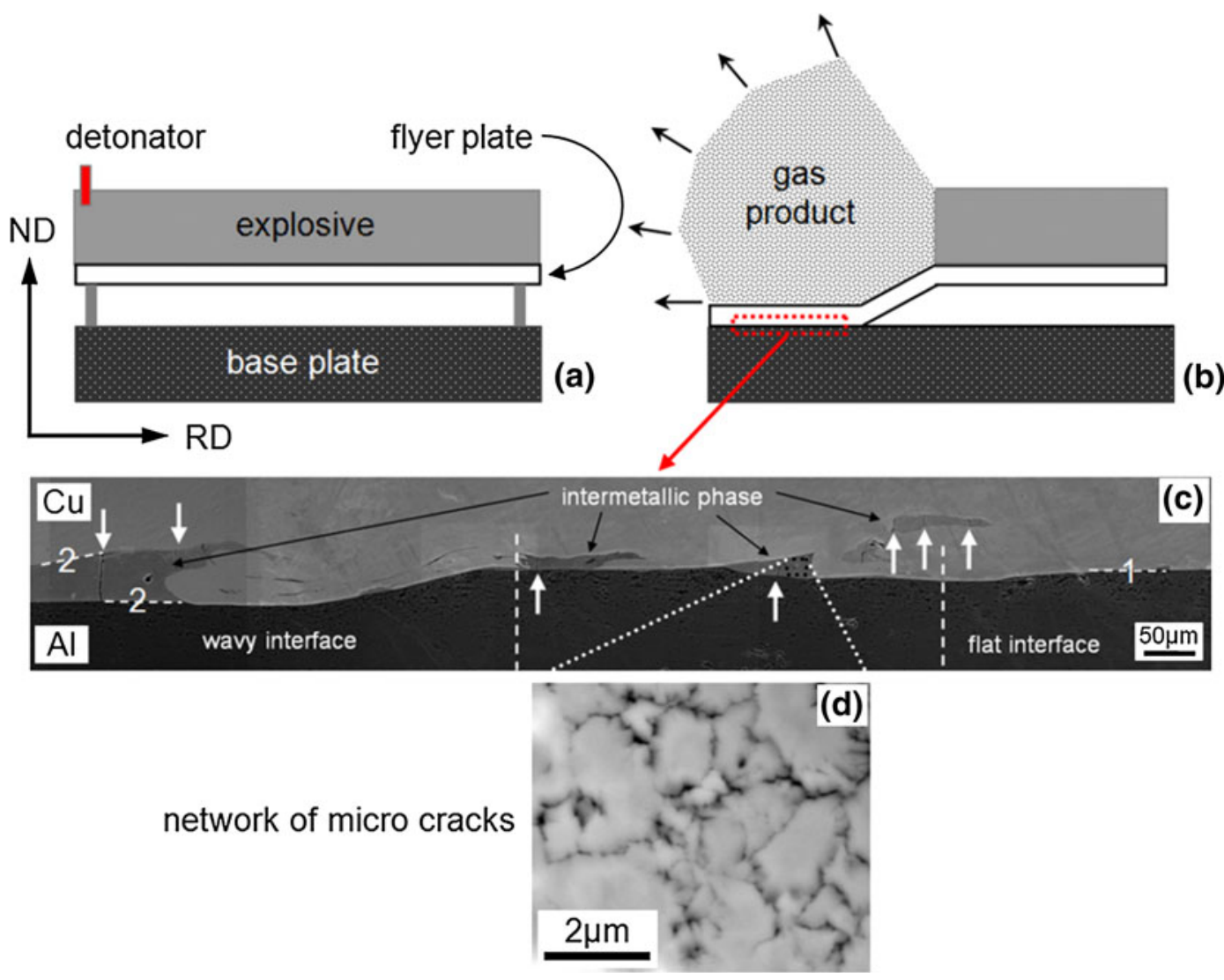

Fig. 1-Schematic illustration of the explosive cladding setup. (a) Parallel arrangement of the sheets before welding. (b) The shape changes of the flyer plate during the impact on the base plate after explosion. (c) Typical microstructure close to the interface analyzed in this work. (d) Network of microcracks inside the intermetallic inclusion. SEM observations in secondary electrons. The interface: 1 - (pure metal)/(pure metal) type; and 2-(pure metal)/(intermetallic inclusion) type (Color figure online).

expected, e.g. ${ }^{[17,18]}$ The intermetallic inclusions can be crystalline, amorphous, or their internal structure can be a mixture of nanocrystalline and amorphous phases. The crystalline or glassy nature of the solidified melt depends strongly on the chemical composition of bonded sheets, e.g., amorphous phases near the interface were observed in steel/Ti clad, ${ }^{[8]}$ whereas the amorphous phases and nanograins were identified in the bonding zone of the Titanium/titanium ${ }^{[11]}$ and in steel $/ \mathrm{Zr}^{[19]}$ explosive claddings.

Explosive weld microstructures have been examined for half a century. In these works, the techniques of optical microscopy, scanning electron microscopy (SEM), and mechanical testing were used for the microstructural analysis and the clad properties' characterization, e.g. ${ }^{[1-16]}$ Particular attention was paid to describing the influence of the technological parameters, such as the detonation energy, the distance between the plates, and the inclination angle of the flyer plate, on the "quality of the weld." The literature data dealing with the morphology and the changes in the chemical composition close to the bonding interface based on the SEM-scale analyses are also relatively rich.

Significantly fewer publications have been issued on the nanoscale transmission electron microscopy (TEM) observations of the phenomena that occur within the intermetallic inclusions and the parent metals adhering to the interface. They were limited to selected metals compositions, e.g., the steel/Ti clad, ${ }^{[5,8]} \mathrm{Ti} / \mathrm{Ti}$ clad, ${ }^{[11]}$ copper to copper clad, ${ }^{[5]}$ or a Ni-based amorphous or metallic glass film clad on stainless steel. ${ }^{[13]}$ However, among those works, only the paper by Song et al. ${ }^{[8]}$ on steel to Ti clad soundly characterizes nanoscale events observed inside intermetallic inclusion. Nothing has been done, to our knowledge, in respect to microstructure characterization of the intermetallic inclusions of $\mathrm{Cu} / \mathrm{Al}$ clad.

It is, therefore, the aim of this work to characterize at the micro-/nanoscale the events that occur near the interface in the $\mathrm{Cu} / \mathrm{Al}$ cladding system. The chemical composition changes inside intermetallic inclusions, their internal microstructure, and the dislocation structure changes observed inside the parent metallic sheets adhering to the interface were of special interest. The investigations of the reaction products formed at the cladding interface were carried out mostly by means of TEM. The different electrochemical properties of bonded metals necessitated the application of the focus ion beam (FIB) technique for the thin foils' preparation from the areas covering the interfaces. Finally, the events occurring during the intermetallic phase's formation under dynamic load were discussed in relation to 
those observed in the static terms of aging after bonding by application of other bonding techniques.

\section{MATERIALS AND EXPERIMENTAL PROCEDURES}

\section{A. Materials and Initial Microstructure of Sheets}

Commercial purity aluminum (AA1050) and copper (M1E-99.5 pct) were used to manufacture $\mathrm{Al} / \mathrm{Cu}$ composites. The thickness of the base (Al) and the flyer $(\mathrm{Cu})$ plates was 25 and $3 \mathrm{~mm}$, respectively, whereas their width and the length were $2000 \mathrm{~mm} \times 4000 \mathrm{~mm}$. The surfaces of the plates were used as received. The composites were obtained by means of the constant stand-off explosive cladding technique. A detonator was placed in the middle of the plate's width close to one of the edges. In the middle of the plate's width, the jetting direction was parallel to the rolling direction (RD). The stand-off distance was $3 \mathrm{~mm}$, whereas the measured explosive detonation velocity was $2200 \mathrm{~m} / \mathrm{s}$. Samples for further microscopic observations were cut off from the end parts of the sheet.

The cases of the "well-welded" sheets were analyzed in this work. A macroscopically acceptable weld was produced since the strength of the weld was higher than the strength of the weaker of the two components. Additionally, the electrical conductivity was on an acceptable level. In the case of the $\mathrm{Cu} / \mathrm{Al}$ clad, the electrical conductivity is, beside the strength, one of the most important properties in industrial applications. The conductivity of intermetallic compounds is about one-seventh of the conductivity of copper and one-fifth of the conductivity of aluminum. ${ }^{[20]}$ This indicates that the total conductivity sharply decreases due to the intense formation of volumes of the solidified liquid. Therefore, the applied technological settings of bonding "produced" interfaces with only a small quantity of intermetallic inclusions. The explosion welded materials evaluated in this study were standard explosion clad products produced by High Energy Technologies Works "Explomet" (Opole, Poland).
The initial microstructures of sheets, i.e., before cladding, were analyzed in a section perpendicular to the transverse direction (TD) using a Zeiss Supra 55VP scanning electron microscope (SEM) equipped with a high resolution electron backscattered diffraction (EBSD) facility. The voltage of $20 \mathrm{kV}$, the working distance of $10 \mathrm{~mm}$, and the specimen tilt angle of $70 \mathrm{deg}$ were used. The microscope control, pattern acquisition, and indexing were done using the TSL OIM Analysis 5 software. The mappings were carried out in the beamscanning mode with the step size of $500 \mathrm{~nm}$ (for $\mathrm{Cu}$ ) or $100 \mathrm{~nm}$ (for $\mathrm{Al}$ ). In the ND-RD section (where ND is the normal direction), the copper plates exhibited equiaxed grains with the average grain diameter of $30 \mu \mathrm{m}$, whereas the aluminum plates were characterized by a microstructure typically observed after hot rolling, i.e., composed of layers of very flat grains. In the ND-RD section, the (average) dimensions of the elongated grains along the longer and the shorter axes equaled about 100 and $15 \mu \mathrm{m}$, respectively (Figure 2).

\section{B. Microstructure Observations and Strain Hardening Analysis Close to the Interface}

After welding, the microstructure observations were carried out in a broad range of scales with the use of an optical microscope (OM), as well as a scanning (SEM) and a transmission (TEM) electron microscope. All the specimens for the microscopic observations were cut off from the bonded sheets perpendicularly to the TD, in the middle of the plate's width. The optical microscope was used for sample scale observations on the mechanically and chemically polished sections. The more detailed structural analyses were performed by means of SEM, with the use of FEI E-SEM XL30. The observations of the dislocation structure in the areas placed about $0.5 \mathrm{~mm}$ from the interface (for both sheets) were performed with the application of CM20 PHILIPS TEM. In this case, the standard procedure of thin foil preparation (separately for the $\mathrm{Al}$ and the $\mathrm{Cu}$ parts), by means of twin-jet electro-polishing with the use of TenuPol-5, was applied.
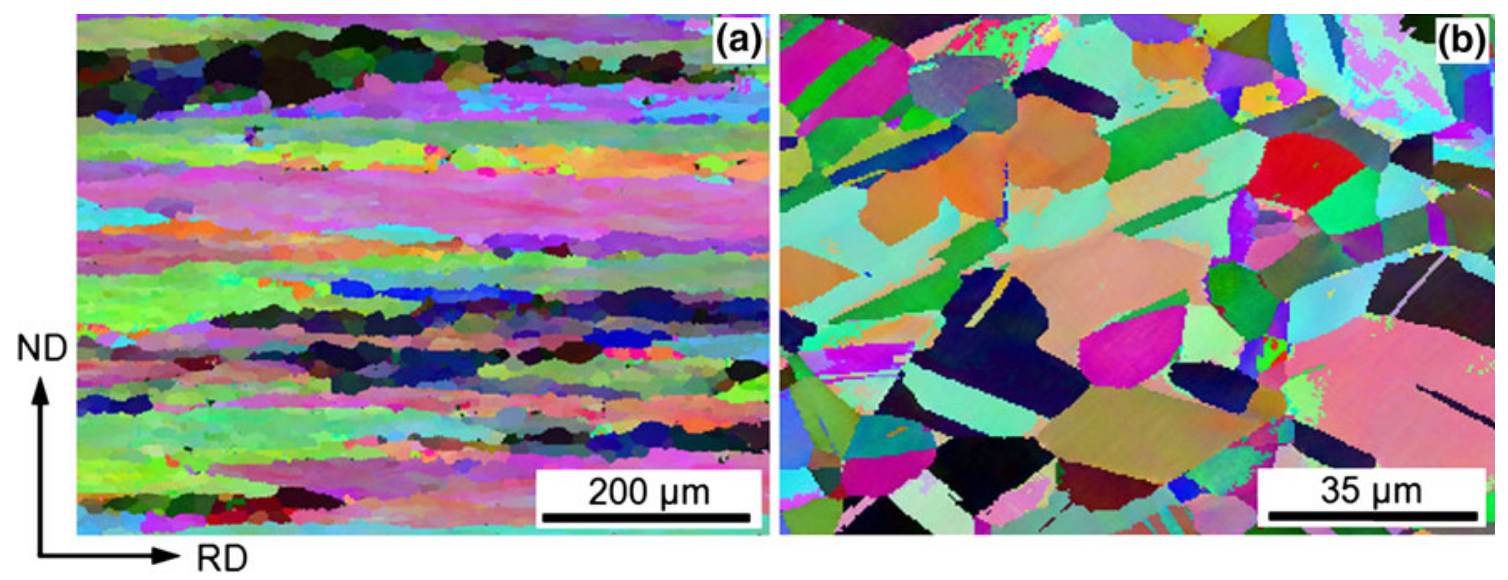

Fig. 2-Initial microstructure of $(a)$ aluminum and $(b)$ copper sheets, observed in the ND-RD section. SEM/EBSD measurements with step size of $100 \mathrm{~nm}(\mathrm{Al})$ and $500 \mathrm{~nm}(\mathrm{Cu})$. Inverse pole figure (IPF) color code was applied (Color figure online). 
The Vickers microhardness measurements were performed to estimate the changes in hardening across the weld interface in a ND-RD section. The test was carried out on a finely polished longitudinal section; the grid papers and the diamond pastes were used to polish the samples cut off from the clad by spark machining. The loads of 10 and $100 \mathrm{G}$ by a sharp needle tip were used for all the indentations. The obtained microhardness values were the average of 3 or 5 indentation measurements.

\section{TEM Analysis of Structure and Chemical Composition Changes Across the Interface}

The microstructure observations and the measurements of the chemical composition changes across the interface were performed by means of TEM with the use of a FEI Technai $\mathrm{G}^{2}$ microscope, operating at the accelerating voltage of $200 \mathrm{kV}$. The TEM was equipped with a field emission gun and a high-angle annular dark field scanning/transmission detector (HAADF/STEM), combined with an EDAX $^{\mathrm{TM}}$ energy dispersive X-ray (EDX) microanalyzer. The resolution of the TEM/EDX system was $\sim 1 \mathrm{~nm}$.

Because of the different electrochemical properties of the welded metals, the classical technique of thin foil preparation by means of electrolytic polishing was not adequate here. Therefore, for nanoscale analyses of the microstructural and the chemical composition changes across the interface, the FIB cutting was applied for the thin foils' preparation along the ND-TD section. In that case, the FEI FIB (FB2000A) instrument operating at $30 \mathrm{kV}$ was used.

\section{RESULTS}

\section{A. Macro-/Mesoscale Structural Observations}

The light microscopy inspection of the joint and the SEM imaging in the backscattered electrons reveals a structure without visible separations between the joined plates (Figure 1(c)). The most important features observed at macroscale are summarized below.

- The morphology of the present joint was characterized by the mixture of wavy and flat patterns. A significant part of the interface was without intermetallic inclusions. The intermetallic inclusions, if they occur, were preferentially located near the front slope of the waves or within the vortex of the waves.

- The average values of the amplitude and the period of the waves equaled 40 to 60 and 300 to $400 \mu \mathrm{m}$, respectively.

- The shape of the waves was asymmetric. The observations show that the interface between the intermetallic inclusions and aluminum sheet was relatively flat, while the interface between the copper and intermetallic inclusion was wavy. Although both types of interfaces showed signs of excessive melting and the formation of hard intermetallics, those directly below the aluminum layer are much thicker than those below the copper ones, as also noticed earlier, e.g., ${ }^{[14]}$ for the same explosively welded metal compositions. This observation could be correlated with melting points of welded metals. ${ }^{[4]}$ According to Ishii et al., ${ }^{[21]}$ when the two metals with significantly different melting points were explosive welded, the wavy morphology was observed only at the interface between the intermetallic inclusion and the metal with a high melting point.

- The presence or absence of intermetallic inclusions leads to the "creation" of one of the two types of interface, i.e., pure metal-solidified melt or pure metal-pure metal. The interfaces around the intermetallic inclusions and between $\mathrm{Al}$ and $\mathrm{Cu}$ sheets were always very sharp. This suggests strong chemical composition changes across the boundary. In some places, the solidified melt was locked inside the "harder" parent metal (i.e., copper). This led to the formation of volumes resembling multilayered sandwiches, in which the intermetallic inclusions were separated by the parent material (copper), as discussed in previous work. ${ }^{[22]}$

- The cracks within the brittle intermetallic inclusions were observed. The macrocracks visible in the light microscope scale were mostly situated perpendicular to the interface, whereas the finer ones, which had been observed only in the SEM scale, formed a non-regular network of microcracks (Figure 1(d)). The cracks were always limited to the melted zone and did not show any tendency for propagation across the base materials, either in the copper or in the aluminum sheet.

- Another characteristic feature is the formation near the interface of the extremely fine-grained structure with the grains that were mostly elongated parallel to the impact direction. In the copper plate, the strongly elongated grains within the wavy region took a characteristic shape reflecting the rotational character of the material displacement. However, this directionality (in both metals) was very quickly lost as the distance from the interface increased. For more details of the waves microstructure and texture, see. ${ }^{[22,23]}$

\section{B. Microhardness Near the Joint}

In order to evaluate the distribution of the strainhardened zones close to interface, the OM and the SEM analyses were supported by the Vickers microhardness testing. The measurements were performed in the ND-RD section (along ND), across the area of the intermetallic inclusion. The results are shown in Figure 3.

The microhardness of the copper and the aluminum sheets before cladding was 110 and $45 \mathrm{HV}$ ( $\pm 2 \mathrm{HV}$ ), respectively. In the state after bonding, the measurements show that values of microhardness similar to 

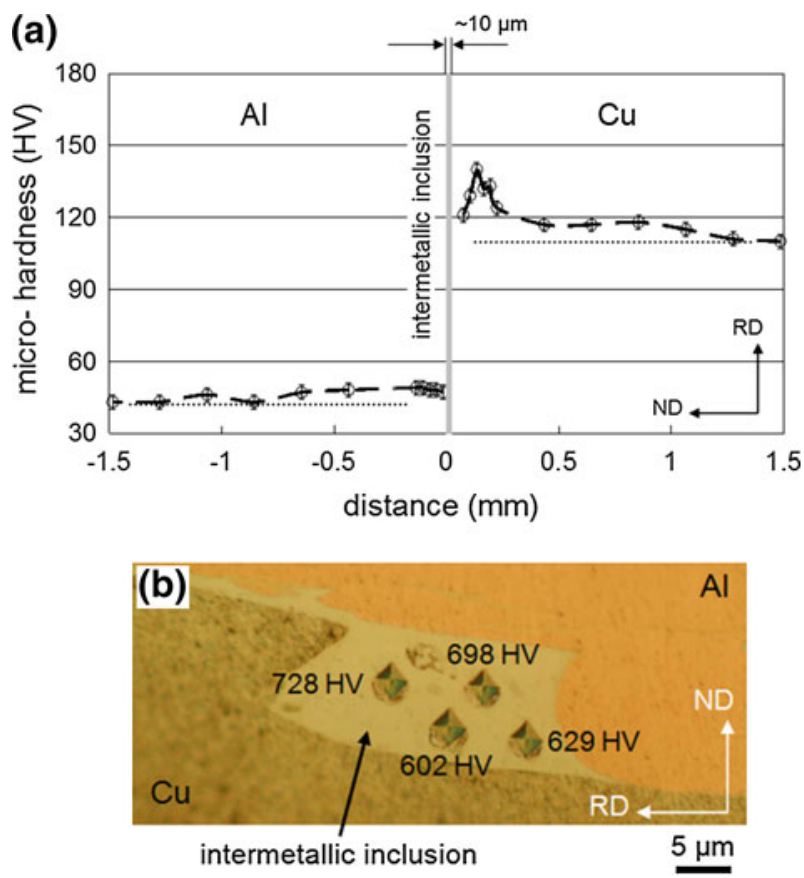

Fig. 3-Vickers microhardness distribution near the interface. (a) "Line scan" across the $\mathrm{Cu} / \mathrm{Al}$ interface. (b) Optical microscopy micrograph showing intermetallic inclusion with marked values of microhardness. The dotted horizontal lines marked in (a) showing the average microhardness of the fully recrystallized (initial) sheets (Color figure online).

those of initial states were observed up to distances of 1.2 to $1.5 \mathrm{~mm}$ from the interfaces. At distances closer to the interface, a systematic increase of microhardness has been observed as the welded surface was approached. The maximal values of microhardness were obtained (in both sheets) in areas distanced 150 to $200 \mu \mathrm{m}$ from the interface; they were $\sim 132$ and $\sim 50 \mathrm{HV}$ for $\mathrm{Cu}$ and $\mathrm{Al}$, respectively. The values of microhardness significantly declined in the very thin layers directly adhering to the interface, independent of the analyzed sheet. (Similar strain hardening changes were observed in stainless steel. ${ }^{[7]}$ ) This probably arises from the balance between the hardening and softening processes due to deformation and dynamic recrystallization. The changes in strain hardening and grain refinement were especially visible in the copper sheet.

The microhardness values inside the solidified melt very often reached $700 \mathrm{HV}$ and were several times higher than those observed in the strongly refined (and hardened) layers of the copper plate, close to the interface. However, in that case, a high scatter of the microhardness values was observed (Figure 3(b)).

\section{Microstructure of the Layers Near the Cu-Al Joint}

A detailed TEM microstructure characterization of the layers directly adhering to the interface was performed on thin foils prepared by means of the FIB technique. Five thin foils, cut off from the sample across different intermetallic inclusions, were analyzed in this work. Independent of the analyzed place, the obtained results, i.e., the description of dislocation structure and chemical composition changes, were similar.

The thin foil, presented in Figure 4, was cut off from the sample area containing a $\sim 10-\mu \mathrm{m}$-thick intermetallic zone. As expected, two distinct interfaces of the pure metal-intermetallic inclusion type, clearly separating the $\mathrm{Al}$ and $\mathrm{Cu}$ sheets, were observed. Figure 5(a) shows the typical bright field TEM micrographs across the whole thickness of the intermetallic layer and the areas of parent sheets adhering to the interfaces. The most important microstructural features observed at the TEM scale are summarized below.

- No cracks or voids existed in the analyzed reaction layer.

- Some of the grains within the intermetallic layer resemble dendrites with clearly marked cores and arms. The diameter of these grains was between 0.5 and $2 \mu \mathrm{m}$. They show typical crystalline contrast during tilting in the TEM.

- The microstructures of the $\mathrm{Al}$ and the $\mathrm{Cu}$ sheets in the areas adhering to the intermetallic layer were different. In aluminum (Figure 5(b)), elongated subgrains with regular dislocation arrangements were often observed. The (sub)grain** length was in the

\footnotetext{
**it could be noted that bright field imaging counts all types of boundaries, i.e., low and high angle, without distinction.
}

order of a few microns, whereas the width was between 200 and $400 \mathrm{~nm}$. In the $\mathrm{Cu}$ sheet, the microstructure was composed of small, nearly equiaxed grains with recrystallization twins and randomly distributed dislocations. The grains' diameter ranged between 0.5 and $1 \mu \mathrm{m}$ (Figure 5(c)).

- The elongated shape of (sub)grains in the Al sheet and randomly distributed dislocations in the $\mathrm{Cu}$ sheet clearly indicated that during welding, the deformation processes were prevailing over softening ones.

\section{Dislocation Structure of the Plates in the Areas Distanced $0.5 \mathrm{~mm}$ from the Interface}

The observations of the dislocation arrangement in copper and aluminum sheets in the layers adhering to the interface were completed by the microstructure characterization in the areas distanced $\sim 0.5 \mathrm{~mm}$ from the interface. In that case, the classical electro-polishing technique for thin foil preparation was applied, separately for copper and aluminum parts.

In both materials, a well-defined cellular dislocation structure was observed. In the Al sheet, the dominating structure (Figure 6(a)) was composed of elongated cells of 2 to $5 \mu \mathrm{m}$ width and $\sim 10 \mu \mathrm{m}$ length. The interior of the cells contained dislocations organized in more or less regular arrangements (Figure 6(b)). In the case of the copper sheet, the dislocation slip led to well-defined dislocation cells, as typically observed in the cold-rolled (up to moderate strains) sheets; both equiaxed and 

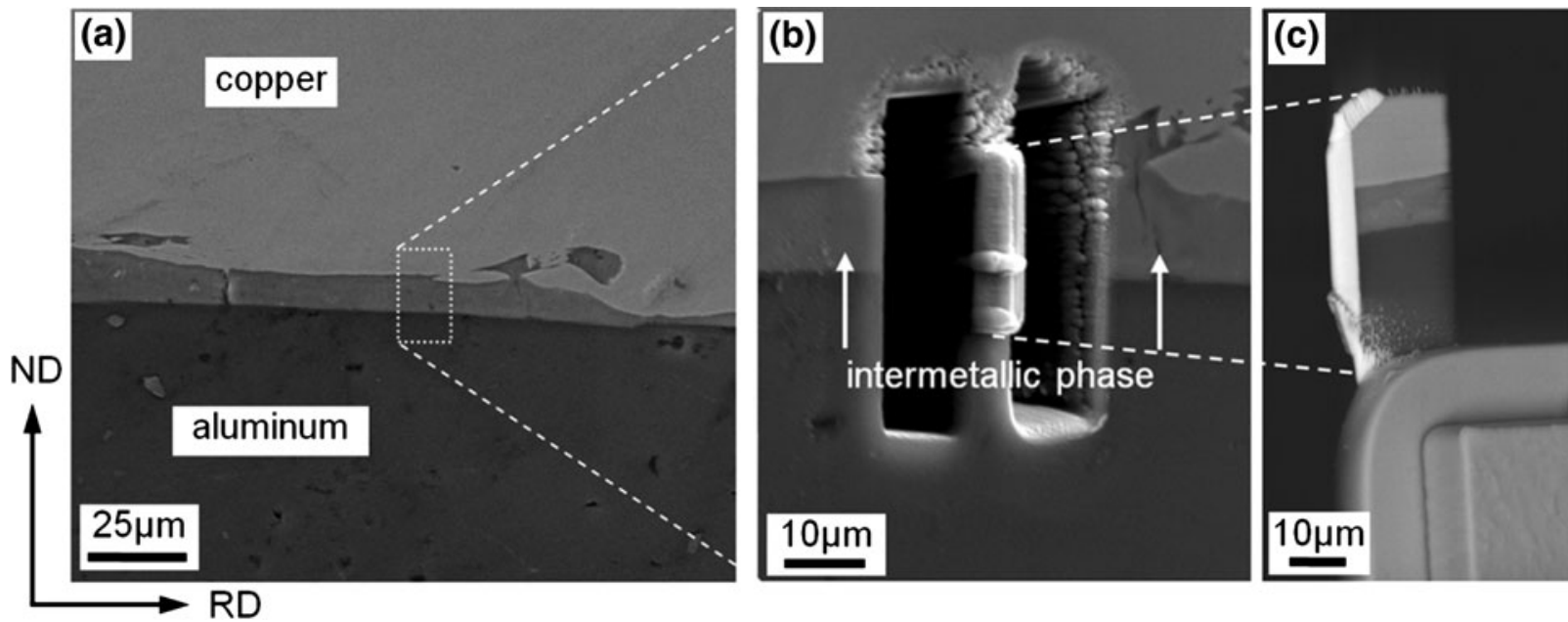

Fig. 4 - (a) Microstructure of the welded sheets close to the interface showing the area selected for FIB cutting. (b) First step of FIB cutting. (c) TEM sample welded to the copper holder. SEM observations in secondary electrons.
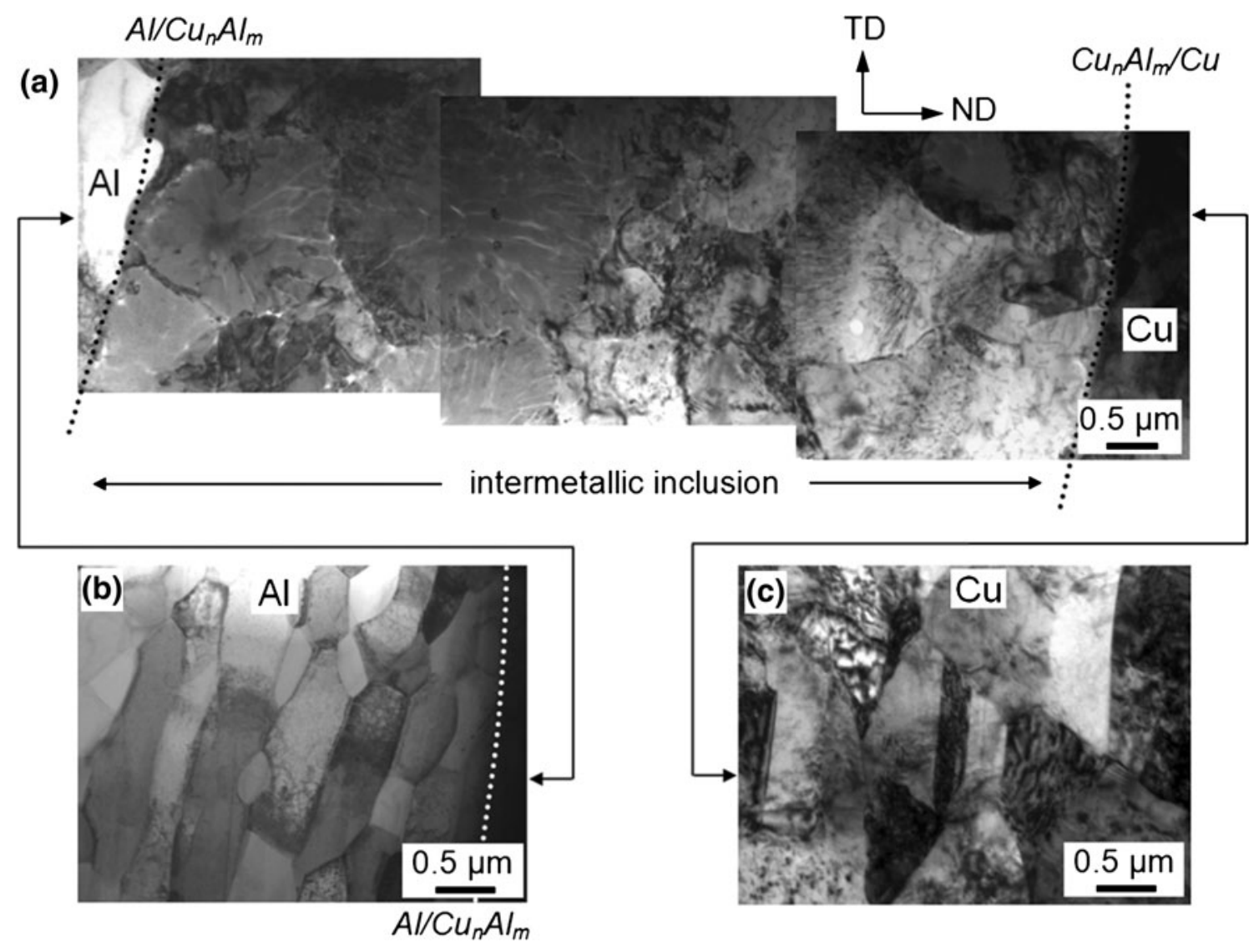

Fig. 5-Microstructural changes across the interfacial zone. (a) Dendrites inside the intermetallic inclusion. Microstructures of the base plates in areas directly adhering to the intermetallic inclusion: $(b)$ elongated subgrains inside the aluminum sheet and $(c)$ fine grains inside copper sheet. TEM bright field images in the ND-TD section.

elongated cells were observed (Figures 7(a) and (b)). The mechanism of deformation by slip was supported in some areas by deformation twinning, i.e., very thin deformation twins occurring against the background of the dislocation cells, as visible in Figure 7(c) and also observed earlier by Carpenter. ${ }^{[5]}$ The primary grain boundaries in the case of both metals and the recrystallization twin boundaries within the copper sheet (Figure 7(d)) were still clearly visible. Moreover, the dislocation arrangements did not show any tendency to cross over these boundaries, as presented in Figures 6 and 7. 

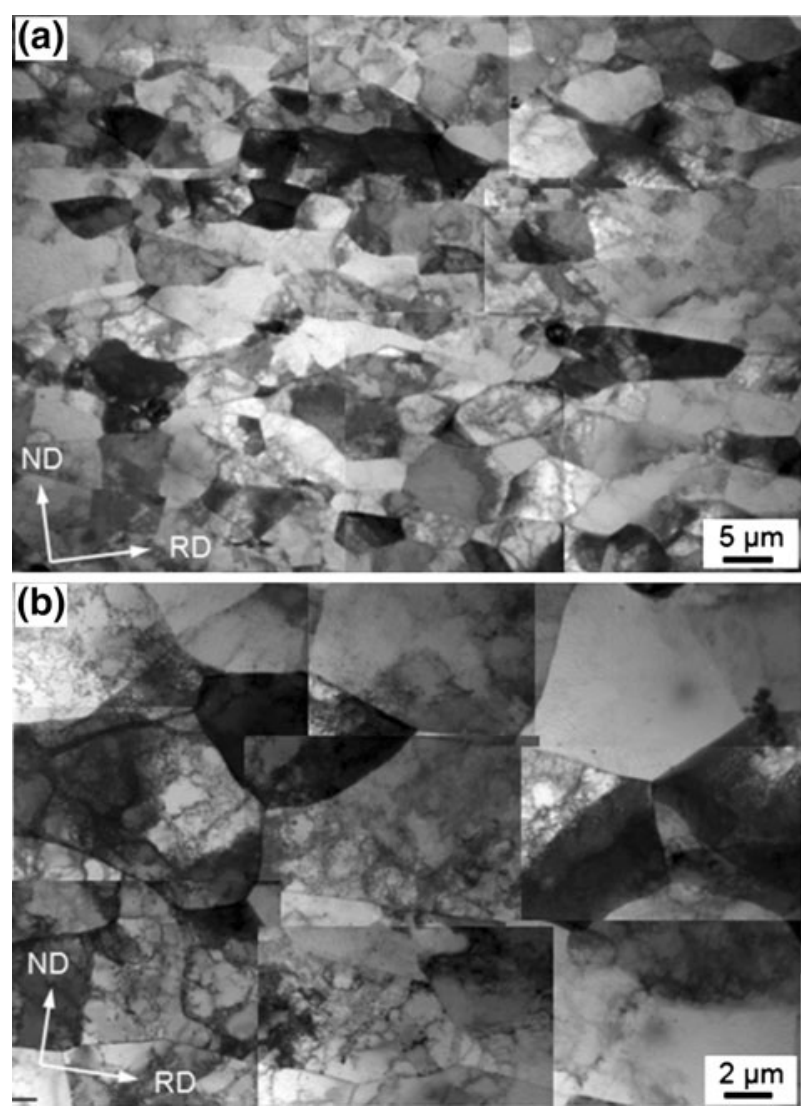

Fig. 6-TEM bright field images showing the dislocation structure of the aluminum sheet in the area distanced about $0.5 \mathrm{~mm}$ from the interface. (a) The structure of the elongated subgrains and (b) microstructure observed at a higher magnification showing the formation of the dislocation cells; ND-RD section.

\section{E. Chemical Composition Changes and Phase Constitution Inside the Intermetallic Inclusion}

The regions of intermetallic inclusion observed at the SEM scale reveal a non-uniform swirl-like contrast of various intensities, indicating that these areas were composed of the layers of different compositions. To clarify the mechanism of phase constitutions, the energy dispersive X-ray spectrometry in TEM was used to analyze the distribution of the $\mathrm{Cu}$ and the $\mathrm{Al}$ atoms across the intermetallic layer.

Figure 8(a) shows the HAADF/STEM microstructure in the ND-TD section. In the "after bonding" state, the general observation based on TEM/EDX measurements is that there was no mechanical mixing between the welded metals in the solid state. The distribution of the elements (chemical composition mapping with step size of $2 \mathrm{~nm}$ ), presented in Figures 8(b) and (c), clearly indicates that some chemical composition fluctuations were observed inside the melted volume. Generally, the irregularities in the distribution of both elements were without any interrelation with respect to the parent sheets. What was unexpected was that in most areas, the concentration of $\mathrm{Al}$ close to the $\mathrm{Al} / \mathrm{Cu}_{m} \mathrm{Al}_{n}$ interface was lower than that observed close to the second interface, i.e., $\mathrm{Cu} / \mathrm{Cu}_{m} \mathrm{Al}_{n}$ (where " $m$ " and " $n$ " both mostly ranged from 0.33 to 0.67 ), as presented in Figure 8(b).
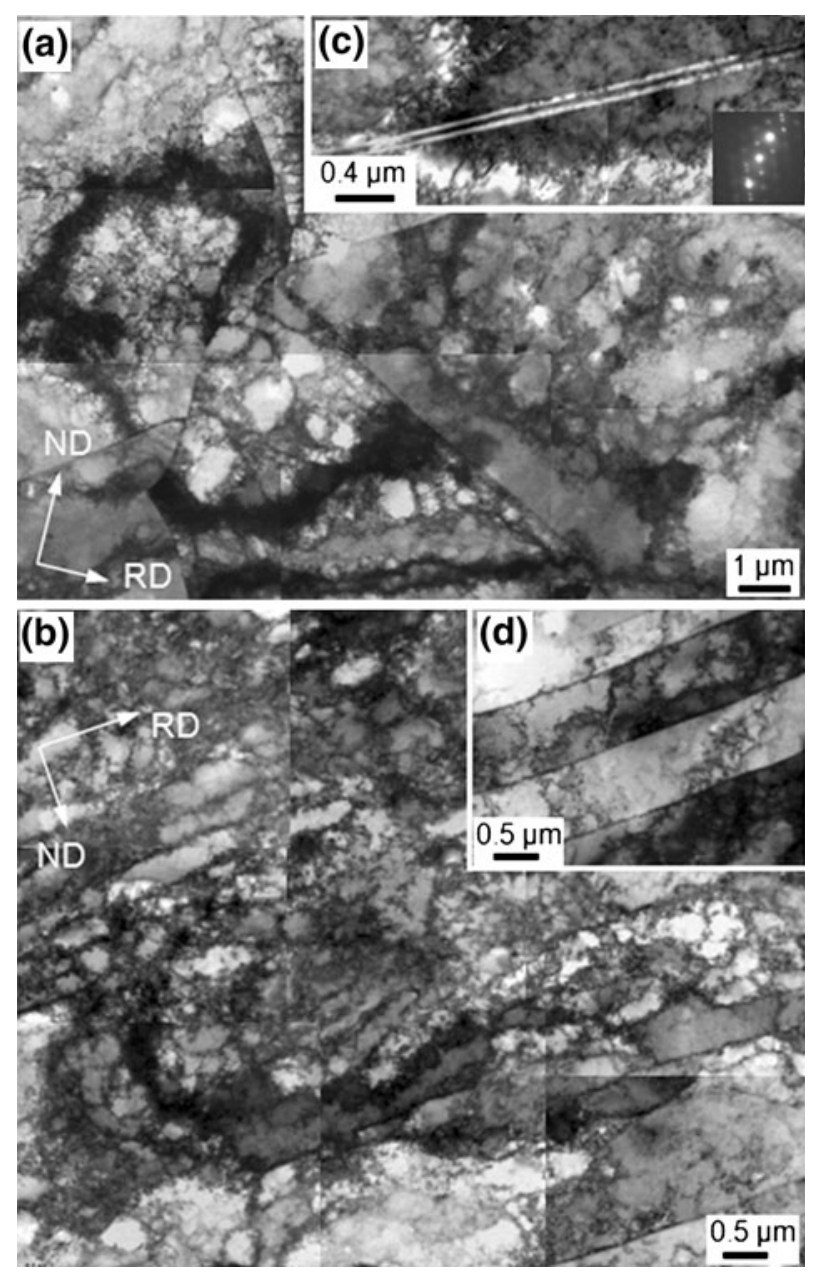

Fig. 7-TEM bright field images showing the dislocation structure of the copper sheet in the areas distanced about $0.5 \mathrm{~mm}$ from the interface. (a) The structure of the equiaxed dislocation cells close to the primary grain boundaries, $(b)$ structure of the elongated cells inside the grain, $(c)$ deformation twins observed against the background of irregular dislocation cells, and $(d)$ recrystallization twins; ND-RD section.

Consequently, the concentration of $\mathrm{Cu}$ close to the $\mathrm{Cu} /$ $\mathrm{Cu}_{m} \mathrm{Al}_{n}$ interface was also lower than that observed on the opposite side (Figure 8(c)). This leads to the conclusion that the processes occurring in the liquid state (the intense stir of the melted metals) were prevailing over those observed in the solid solution. Additionally, the rapid cooling together with the extremely high pressure makes the solidification terms far from equilibrium and thus influences the occurrence of the "metastable" phases.

\section{Metastable phases}

Closer analyses of the chemical composition changes across the intermetallic layer were done along two line scans parallel to the ND (with the step size of $\sim 2 \mathrm{~nm}$ ) and by point measurements. The line scans are marked in the HAADF/STEM image of Figure 9(a) and the results are presented in Figures 9(b) and (c). They show the quantity of the counts for both elements (line K) as a "function" of the beam position. As expected, the area 


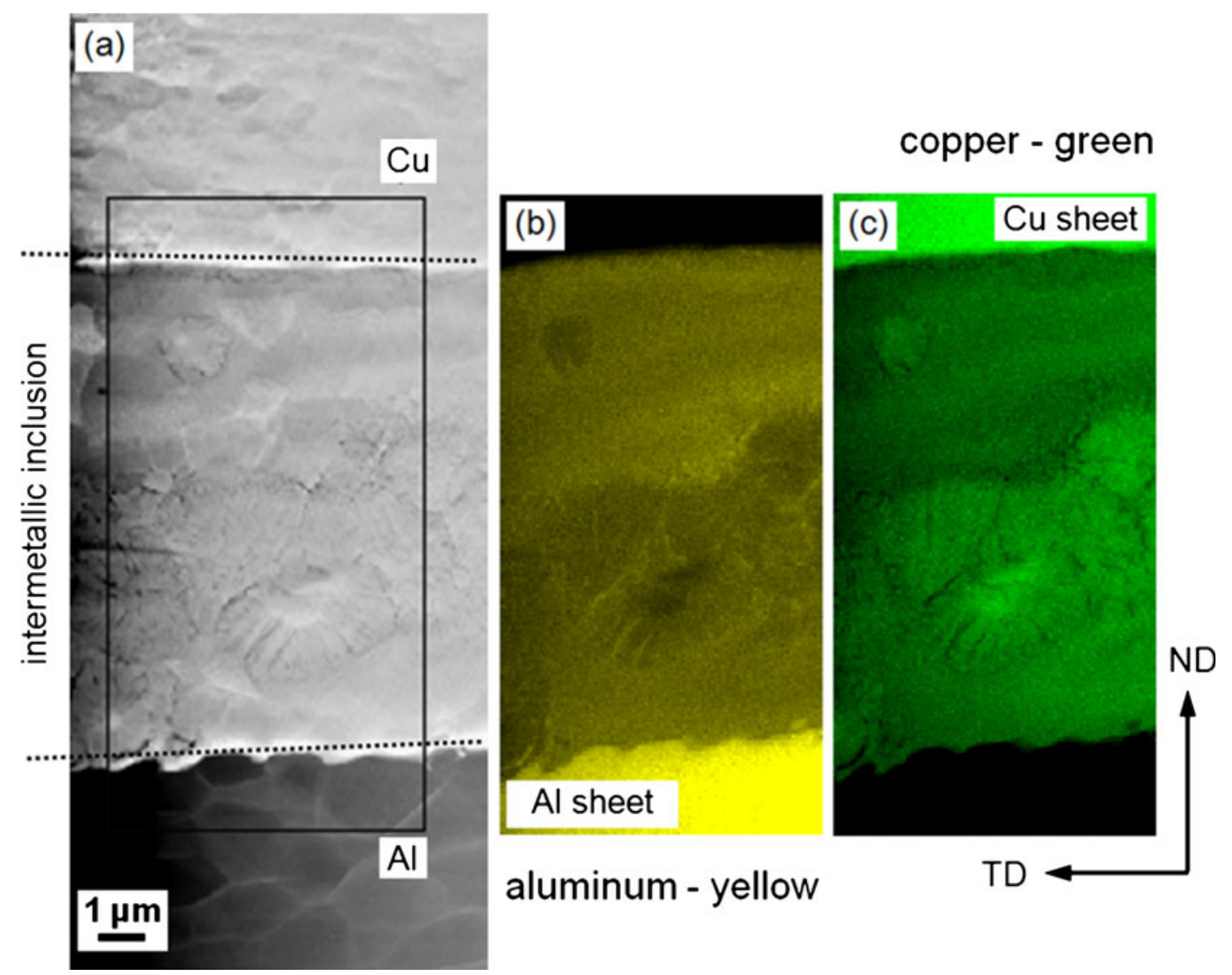

Fig. 8- Chemical composition changes inside the interfacial zone. (a) HAADF-STEM microstructure, $(b)$ and $(c)$ maps showing the distribution of $\mathrm{Al}$ and $\mathrm{Cu}$ elements inside the area marked in (a). TEM/EDX microanalysis. The higher intensities of yellow and green color the higher concentration of $\mathrm{Al}$ and $\mathrm{Cu}$ element, respectively (Color figure online).

of intermetallic inclusion showed strong differences of the X-ray intensity of the $\mathrm{Cu}(\mathrm{K})$ and $\mathrm{Al}(\mathrm{K})$ elements (and indirectly the changes of chemical composition) inside the intermetallic layer, even along the distance of a few nanometers.

The TEM/EDX point measurements reveal again a non-uniform intermixing of the phases, without any interrelation in respect to the parent sheets, as visible in Figure 10. Strong chemical composition changes were observed even inside the particular dendrites. Figure 11 clearly shows that the core of the dendrites is enriched with $\mathrm{Cu}$ and the arms of the dendrite with Al. The results of TEM/EDX point measurements in different areas inside the intermetallic inclusion are summarized in Table I. The results suggest that for most of the observed cases, the average copper/aluminum ratio (in at. pet) varies from about $3: 1$ to $1: 3$, as it was also observed in earlier works, e.g. ${ }^{[22,23]}$ Two other important conclusions could be drawn. Firstly, the high cooling rates (and the high pressure) lead to the "creation" of crystalline intermetallic phases far from that observed on the equilibrium $\mathrm{Cu}-\mathrm{Al}$ phase diagram. Secondly, in all the analyzed areas, the intermetallic phases enriched in $\mathrm{Al}$ were observed most often. This is probably due to the different solubility of $\mathrm{Al}$ in $\mathrm{Cu}$ and $\mathrm{Cu}$ in $\mathrm{Al}$. The solubility limit of $\mathrm{Al}$ in $\mathrm{Cu}$ [e.g., 19.7 pet at $840 \mathrm{~K}$ $\left(567{ }^{\circ} \mathrm{C}\right)$ ] is significantly larger than that of $\mathrm{Cu}$ in $\mathrm{Al}$ [e.g., 2.48 pct at $821 \mathrm{~K}\left(548{ }^{\circ} \mathrm{C}\right)$ ] within a broad range of temperatures. Additionally, the solubility of $\mathrm{Al}$ in $\mathrm{Cu}$ is nearly constant within a very broad range of temperatures, whereas in the case of $\mathrm{Cu}$ in $\mathrm{Al}$, the solubility drastically decreases as the temperature decreases. Although the metastable phases occupied the major part of the intermetallic inclusion, the equilibrium phases were also observed.

\section{Equilibrium phases of $C u_{m} A l_{n}$ type}

The investigations by means of TEM clearly showed the presence of three equilibrium intermetallic phases (i.e., the phases that occur in the equilibrium phase diagram), i.e., $\Theta-\mathrm{CuAl}_{2}, \gamma-\mathrm{Cu}_{9} \mathrm{Al}_{4}$, and $\eta$-CuAl. Nevertheless, the dominance of the $\mathrm{CuAl}_{2}$ phase is the most important common feature observed in all the analyzed thin foils. The equilibrium phases did not form layers, but occupied small, rather irregular, volumes. (It is important to remember that the changes in the concentration of both elements and the occurrence of a given phase inside the solidified melt do not really depend on the distance from the parent materials.)

Figure 12 shows TEM bright field images and the corresponding selected area diffraction (SAD) patterns made in the areas close to the parent plates and in the middle layer of the solidified melt. It is visible that the $\mathrm{CuAl}_{2}$ phase is detected in all the areas across the intermetallic layer. Unfortunately, in accordance with the previous works, the $\mathrm{CuAl}_{2}$ phase plays an important 

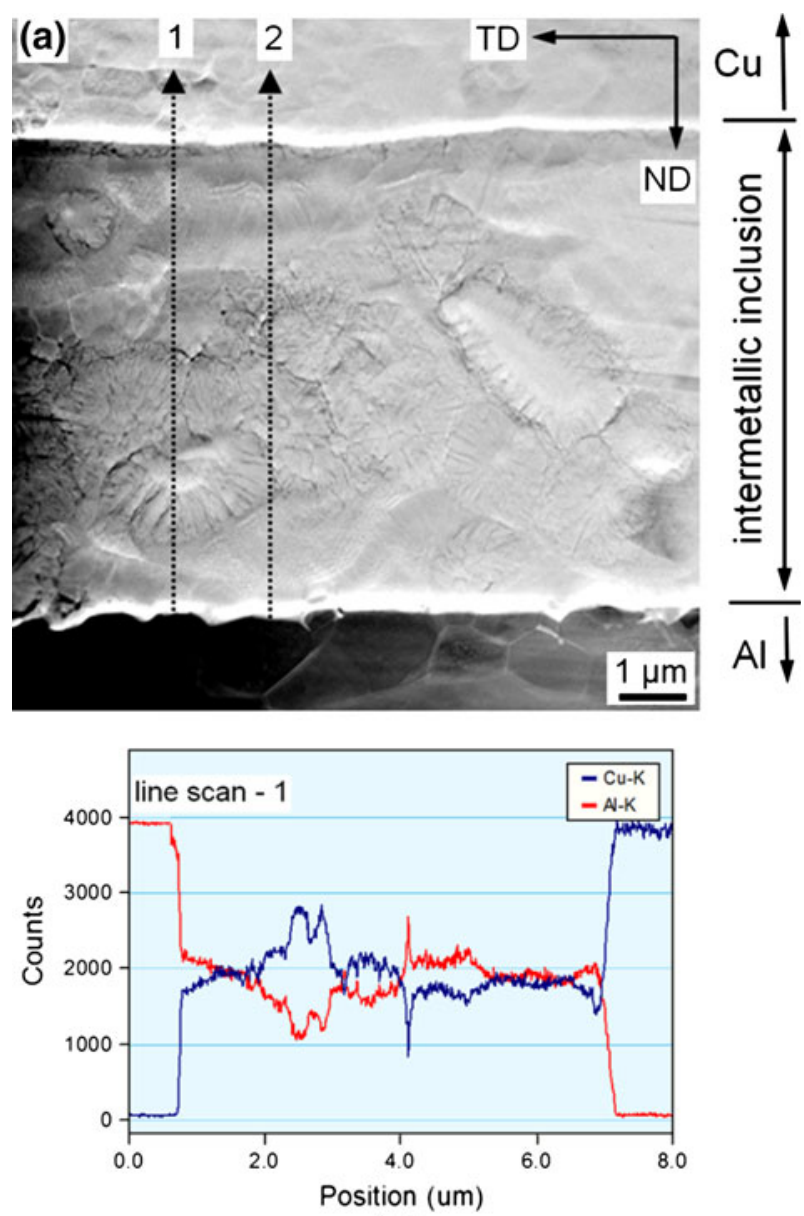

(b)

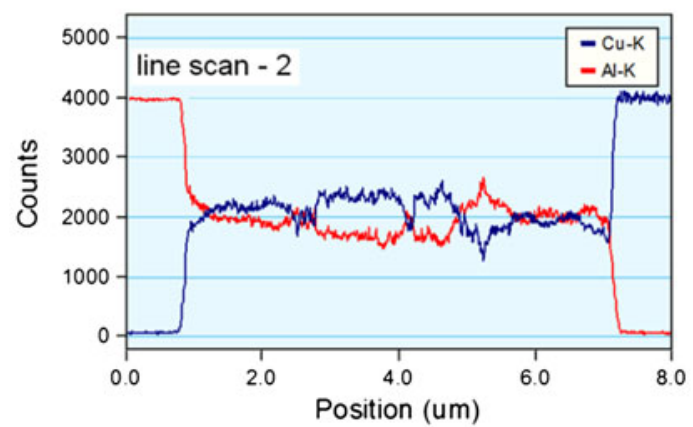

(c)

Fig. 9 - Chemical composition changes across the intermetallic zone. (a) HAADF-STEM microstructure, $(b)$ and $(c)$ line scans showing the changes of quantity of the counts across the intermetallic inclusion (Color figure online).

role with respect to the mechanical properties of the joint; as it was showed by Ken et al., ${ }^{[24]}$ most of the fractures occur inside these intermetallic inclusions. The microstructure presented in Figure 13(a) and the attached SAD (Figure 13(b)) patterns document the nucleation of the $\mathrm{Cu}_{9} \mathrm{Al}_{4}$ phase, which was located close to the $\mathrm{Al}$ sheet. In the middle of the intermetallic zone, the $\mathrm{CuAl}$ phases were often detected (Figures 13(c) and (d)).

\section{The interfaces between pure metals} and intermetallic inclusion

The boundary zone between the solidified melt and the aluminum plate was different from that between the solidified melt and the copper plate. The formation of very small grains (up to $50 \mathrm{~nm}$ in diameter), growing from the interface to the inside of the intermetallic layer (Figure 14(a)), was the main feature observed close to the $\mathrm{Cu} / \mathrm{Cu}_{m} \mathrm{Al}_{n}$ interface. The chemical composition and the structure of the fine grains mostly fit well with the $\mathrm{Al}_{2} \mathrm{Cu}$ phase. Although the process of small grains' nucleation was dominant, there were areas close to the boundary occupied by thin, almost continuous, layers of a different chemical composition, even along the distances of a few nanometers (Figure 14(b)). In the neighboring areas, the concentration of atoms of both elements varied from $\sim 50$ to $\sim 75$ at. pet for aluminum and from 25 to 50 at. pet for copper.

The $\mathrm{Al} / \mathrm{Cu}_{m} \mathrm{Al}_{n}$ interface was sharper. In that case, the changes in the chemical composition close to the interface, if at all, were too small to be detected by the standard TEM/EDX analysis.

\section{DISCUSSION}

The microstructure of the interface region of the copper/aluminum explosive joint was studied at the micro- and nanoscale levels. Particular attention was paid to the structural changes near the interface and the chemical composition changes in the intermetallic inclusions.

\section{A. Morphology of the Weld Interface-Macroscopic Analysis}

The morphology of the present joint was characterized by the mixture of wavy and flat structure, with only a small quantity of intermetallic inclusions. A similar, non-regular appearance of the interface was also observed, e.g., by Salem et al., ${ }^{[14]}$ whereas a very regular and wavy interface was presented by, e.g., Zhang et al. ${ }^{[16]}$ for the same metals' composition. The literature data documented that the amplitude and the wave length increase if the kinetic energy of explosive load increases, e.g. ${ }^{[25,26]}$ This improves the mechanical properties of the clad. But, a very high explosive load and excessive waviness usually lead to the intense formation of intermetallics, as discussed in. ${ }^{[26]}$ In the extreme case of a very high explosive load, the melted zone can take the form of a semi-continuous broad interlayer, usually with a "high density" of macrocracks. ${ }^{[6]}$ Such a bond typically shows high tensile strength, very low ductility, and impact resistance. However, this semi-continuous intermetallic layer significantly decreases the electrical conductivity of the clad, i.e., one of the most important physical property of $\mathrm{Al} / \mathrm{Cu}$ clad.

For specimens welded by a low explosive load, no intermetallic inclusions were detected near the interface. But, this leads to the lowering of the clad strength. Therefore, in the analyzed metal compositions, the 


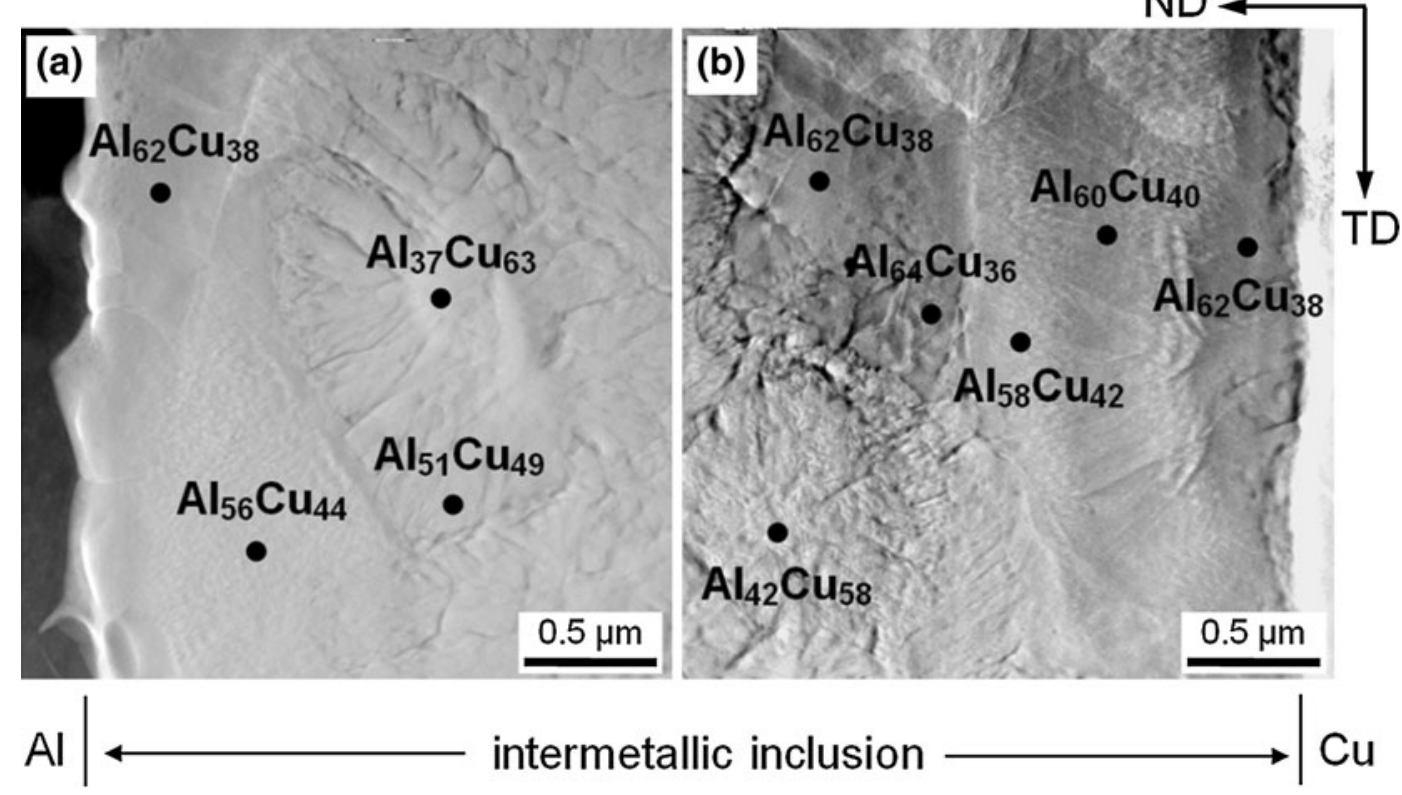

Fig. 10 - Chemical composition changes within the intermetallic inclusion close to $(a)$ aluminum and (b) copper sheets. HAADF-STEM microstructure and results of the TEM/EDX point microanalyses.

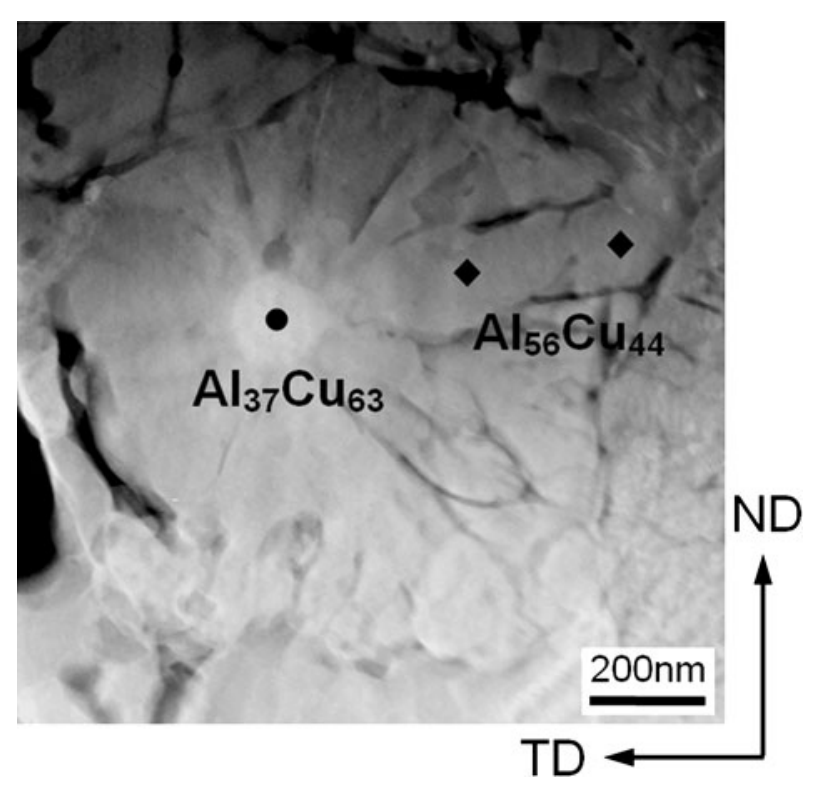

Fig. 11-Chemical composition changes inside the dendrite. HAADF-STEM microstructure and results of the TEM/EDX point microanalyses.

interface that was obtained was a compromise between good electrical conductivity and sufficient strength.

\section{B. Microstructural Changes of Parent Sheets in the Layers Near the Interface}

Explosive welding causes a variety of microstructural changes within the bonding zone. One of the most important features is a pronounced increase of the dislocation density and extremely strong grain refinement in the parent sheet layers near the interface. The most disputable question is if this grain refinement results from rapid crystallization or severe plastic deformation.

Hammerschnidt and Kreye ${ }^{[27]}$ correlated the ultrafine grain formation in the layers near the interface with the processes occurring during rapid crystallization. They observed an almost random orientation distribution of fine grains in the $\mathrm{Al}_{3} \mathrm{Cu} / \mathrm{Al}_{3} \mathrm{Cu}$ alloy cladding system, i.e., the same effect that was noticed after splat cooling of some aluminum alloys. Since the structures observed in this work (near the interface) were highly saturated by dislocations, the explanation of fine-grained structure formation based only on the events observed in the liquid state is strongly disputable.

In the present work, two kinds of fine-grained structures were observed. The fine grains of the $\mathrm{Al}_{2} \mathrm{Cu}$ phase (probably originating from the liquid state) were observed close to the $\mathrm{Cu} / \mathrm{Cu}_{m} \mathrm{Al}_{n}$ interface. But, the grains were growing from the interface to the inside of the intermetallic layer and did not form a compact layer. In the parent sheets, the fine grains were observed (in the TEM bright field images) in layers near the interface. They were similar to those observed in the previous work based on SEM/EBSD measurements. ${ }^{23]}$ The orientation maps clearly showed that the grains were separated by large angle grain boundaries with misorientations higher than $15 \mathrm{deg}$. Although the total thickness of this fine-grained zone did not exceed a few microns, the layers showed the well-marked coppertype texture components ${ }^{[23]}$ typically observed in highly deformed fcc metals. This clearly indicates that the deformation processes dominate over softening ones and those occurring during rapid crystallization.

The confirmation of this suggestion can be found even in earlier work based on TEM used for the analysis of explosively welded sheets. Some authors observed, 
Table I. Chemical Composition Changes Inside Intermetallic Inclusions

\begin{tabular}{|c|c|c|c|c|}
\hline Point Number & $\begin{array}{c}\mathrm{Al} \\
\text { (at. pct) }\end{array}$ & $\begin{array}{c}\mathrm{Cu} \\
\text { (at. pct) }\end{array}$ & $\begin{array}{l}\text { Predicted } \\
\text { Phase }\end{array}$ & $\begin{array}{l}\text { Description of Point Position } \\
\text { Inside Solidified Melt (SM) }\end{array}$ \\
\hline \multicolumn{5}{|l|}{ Aluminum sheet } \\
\hline $\mathrm{P} 02$ & 55.5 & 44.5 & \multirow{4}{*}{$\mathrm{CuAl}_{2}$} & grains adhering to $\mathrm{Al}$ sheet \\
\hline $\mathrm{P} 03$ & 45.8 & 54.2 & & grains adhering to $\mathrm{Al}$ sheet \\
\hline $\mathrm{P} 12$ & 67.0 & 33.0 & & grains adhering to $\mathrm{Al}$ sheet \\
\hline $\mathrm{P} 14$ & 55.6 & 44.4 & & grains adhering to $\mathrm{Al}$ sheet \\
\hline P15 & 35.9 & 64.1 & $\mathrm{Cu}_{9} \mathrm{Al}_{4}$ & grains adhering to $\mathrm{Al}$ sheet \\
\hline P11 & 36.9 & 63.1 & $\mathrm{Cu}_{9} \mathrm{Al}_{4}$ & core of dendrite $(\sim 1 \mu \mathrm{m}$ from $\mathrm{SM} / \mathrm{Al}$ interface $)$ \\
\hline P13 & 49.0 & 51.0 & \multirow[t]{10}{*}{$\mathrm{CuAl}$} & arm of dendrite $(\sim 1 \mu \mathrm{m}$ from $\mathrm{SM} / \mathrm{Al}$ interface $)$ \\
\hline P01 & 38.2 & 61.8 & & core of dendrite $(\sim 1.5 \mu \mathrm{m}$ from $\mathrm{SM} / \mathrm{Al}$ interface $)$ \\
\hline P31 & 55.9 & 44.1 & & \\
\hline P32 & 36.8 & 63.2 & & space between dendrite arms $(\sim 1.5 \mu \mathrm{m}$ from $\mathrm{SM} / \mathrm{Al}$ interface $)$ \\
\hline P33 & 56.9 & 43.1 & & dendrite $\operatorname{arm}(\sim 1.5 \mu \mathrm{m}$ from $\mathrm{SM} / \mathrm{Al}$ interface $)$ \\
\hline P34 & 55.6 & 44.4 & & dendrite arm $(\sim 1.5 \mu \mathrm{m}$ from $\mathrm{SM} / \mathrm{Al}$ interface $)$ \\
\hline P04 & 52.3 & 47.7 & & grains in the middle of SM \\
\hline P41 & 62.9 & 37.1 & & grains in the middle of SM \\
\hline $\mathrm{P} 42$ & 59.3 & 40.7 & & grains in the middle of SM \\
\hline $\mathrm{P} 43$ & 61.4 & 38.6 & & grains in the middle of SM \\
\hline P44 & 67.0 & 33.0 & \multirow[t]{3}{*}{$\mathrm{CuAl}_{2}$} & grains in the middle of SM \\
\hline P05 & 65.5 & 34.5 & & arm of dendrite $(\sim 2 \mu \mathrm{m}$ from $\mathrm{SM} / \mathrm{Cu}$ interface $)$ \\
\hline P56 & 64.2 & 35.8 & & grain $(\sim 2 \mu \mathrm{m}$ from $\mathrm{SM} / \mathrm{Cu}$ interface $)$ \\
\hline P55 & 67.2 & 32.8 & \multirow[t]{6}{*}{$\mathrm{CuAl}_{2}$} & grain $(\sim 1.8 \mu \mathrm{m}$ from $\mathrm{SM} / \mathrm{Cu}$ interface $)$ \\
\hline P54 & 63.1 & 36.9 & & grain $(\sim 1.5 \mu \mathrm{m}$ from $\mathrm{SM} / \mathrm{Cu}$ interface $)$ \\
\hline $\mathrm{P} 25$ & 61.6 & 38.4 & & grain $(\sim 1.5 \mu \mathrm{m}$ from $\mathrm{SM} / \mathrm{Cu}$ interface $)$ \\
\hline P26 & 42.0 & 58.0 & & core of dendrite $(\sim 1.5 \mu \mathrm{m}$ from $\mathrm{SM} / \mathrm{Cu}$ interface $)$ \\
\hline P06 & 55.6 & 44.4 & & arm of dendrite $(\sim 1.5 \mu \mathrm{m}$ from $\mathrm{SM} / \mathrm{Cu}$ interface $)$ \\
\hline P53 & 64.5 & 35.5 & & grain $(\sim 1.2 \mu \mathrm{m}$ from $\mathrm{SM} / \mathrm{Cu}$ interface $)$ \\
\hline $\mathrm{P} 23$ & 67.5 & 32.5 & \multirow[t]{5}{*}{$\mathrm{CuAl}_{2}$} & grains adhering to copper sheet \\
\hline $\mathrm{P} 24$ & 58.1 & 41.9 & & grains adhering to copper sheet \\
\hline P08 & 58.2 & 41.8 & & grains adhering to copper sheet \\
\hline P51 & 49.1 & 50.9 & & grains adhering to copper sheet \\
\hline P52 & 54.6 & 45.4 & & grains adhering to copper sheet \\
\hline Copper sheet & & & & \\
\hline
\end{tabular}

TEM/EDX point measurements.

e.g., ${ }^{[5,28]}$ an increased density of dislocation, high vacancy concentration, and even microtwins in parent sheets near the interface, i.e., typical effects accompanying severe deformations.

\section{Chemical Composition Changes}

The processes occurring in the intermediate layers of explosively welded composites were sometimes regarded as diffusion-controlled, e.g. ${ }^{[9,11,29]}$ This indicates that all the processes inside the intermetallic inclusions should lead to formation of the phases existing on the equilibrium phase diagram. However, the equilibrium phases were observed only rarely.

Now, the changes in the chemical composition inside the intermetallic inclusions will be discussed from two points of view. Firstly, the chemical composition changes within intermetallic inclusion "created" by explosive welding will be discussed. Secondly, the distribution of elements inside these intermetallic inclusions will be discussed with respect to the diffusion-controlled processes which have been observed in other bonding (or welding) techniques after aging, in conditions close to the equilibrium. The last analysis is also important for the explosively welded sheets. Since the straightening of the sheets after explosive bonding is preceded by annealing, the description of the temperature-induced changes near the interface is of special practical importance.

\section{Chemical composition changes within} intermetallic inclusions

The general observation resulting from the present research is that the possibility of predicting the formation of a particular phase in the intermetallic inclusion in the state "after bonding" is very difficult. This results from the vigorous stirring of the melted volumes due to the high dynamics of the bonding process. From the point of view of the temperature influence, the events taking place during explosive bonding can be attributed to one of the two periods.

In the first period, the temperature increase is dominant with respect to transferring the heat away from areas close to the collision point, which is too slow to be effective. It is widely accepted that the kinetic energy of the jet and the large plastic work of deformation, which are dissipated to heat, induce the melting of the material close to the weld interface. As the process is very fast, there is no time for the heat to be transferred away from 


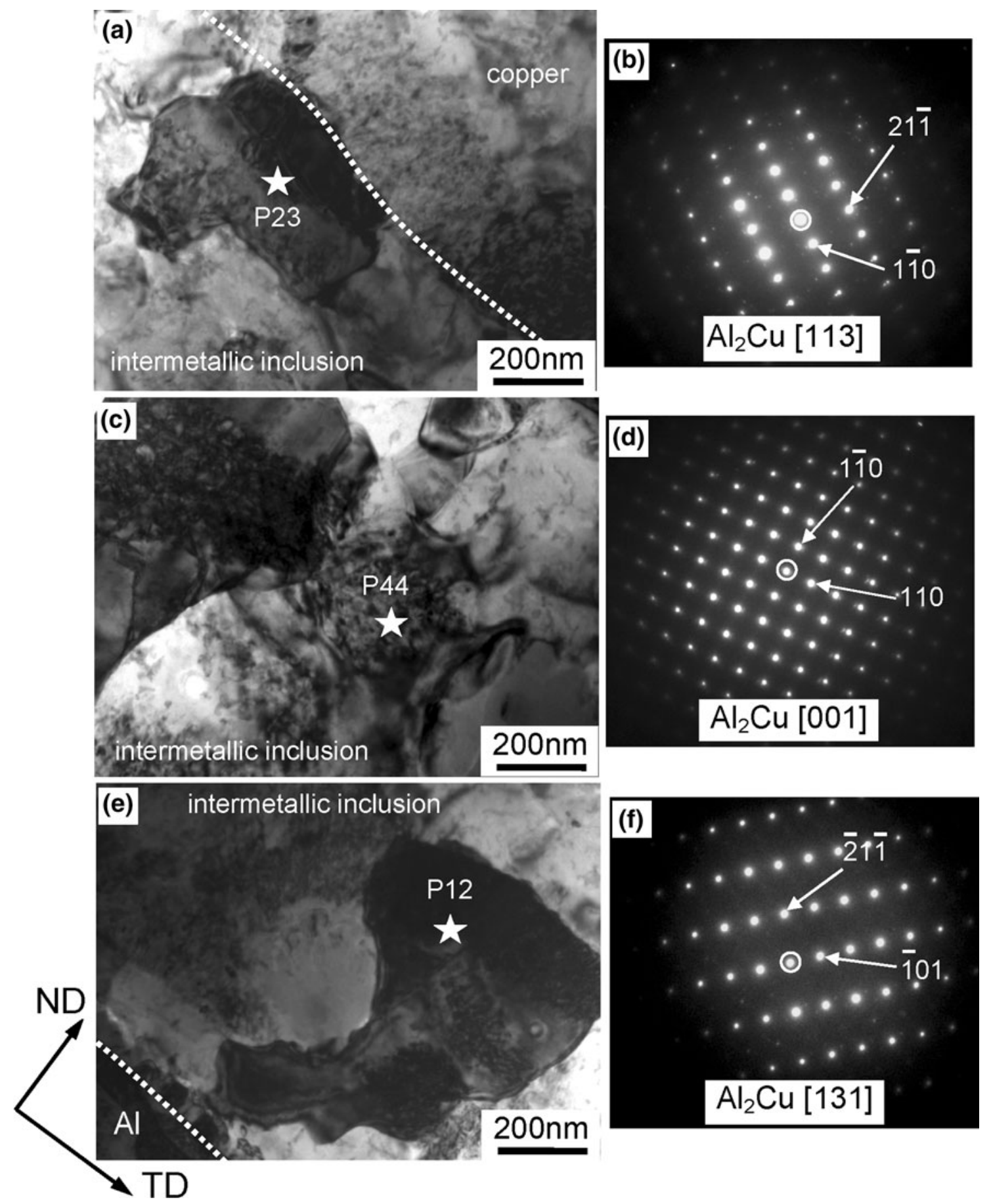

Fig. 12-TEM bright field micrographs and the corresponding diffraction patterns showing the presence of the $\mathrm{Al}_{2} \mathrm{Cu}$ phase in different areas of intermetallic inclusion: $(a)$ and $(b)$ close to the copper sheet, $(c)$ and $(d)$ in the middle of the intermetallic zone, and $(e)$ and $(f)$ close to the aluminum sheet. Chemical composition of marked points is presented in Table I.

the interface, and hence any increase of the temperature and melting is local.

In the second period (as the collision point is moved forward), the cooling processes are dominant. During solidification, the melted volumes are subjected to high cooling rates due to the cold surroundings and the high heat conductivity of metals. At very high cooling rates, the steady-state models overestimate the nucleation rate.
In particular, the positions of liquidus and solidus lines are expected to be quite different from those corresponding to the equilibrium conditions. Depending on the nucleation or the growth temperature, a series of metastable phases can be formed; they do not appear in the equilibrium $\mathrm{Al}-\mathrm{Cu}$ phase diagram.

With respect to the question of why phases absent on classical equilibrium phase diagrams are dominant, 

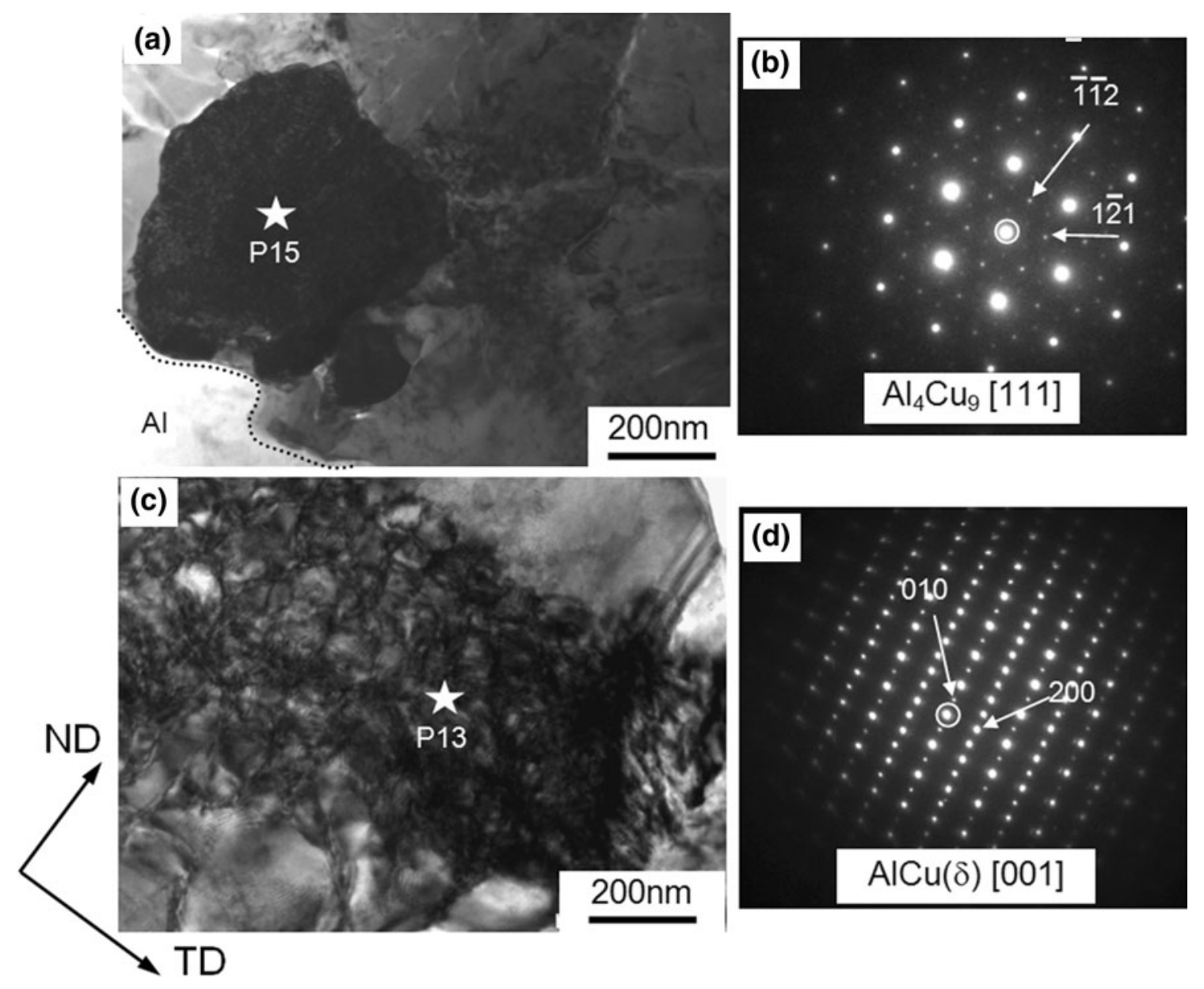

Fig. 13-TEM bright field micrographs and the corresponding diffraction patterns showing the presence of $(a)$ and $(b)-\mathrm{Al}_{4} \mathrm{Cu}_{9}$ phase; $(c)$ and (d) $\mathrm{AlCu}$ phase. Area close to (a) the Al base plate and (b) middle area of the intermetallic layer. Chemical composition of marked points is presented in Table I.

and only occasionally equilibrium phases are formed, it has been assumed that the principal cause of this effect can be attributed to a very high speed of crystallization, high pressure "created" by the moving detonation wave, and strong plastic deformation of the layers near the surface. In particular, the rapid crystallization and high pressure disqualify the classical models of crystallization. Therefore, the exact position of liquidus and solidus lines may be very far from those observed in the equilibrium state. This approach is affiliated to the concept formulated by Martin, ${ }^{[30]}$ according to which high flux of energy to the structure (as a consequence of the plates' collision) may stimulate the change in thermodynamic potential of the alloy in the bond zone.

With respect to the changes in the chemical composition, the analysis is strongly dependent on the scale of observations; each scale reveals characteristic features. ${ }^{[8]}$ The problem arises from the fact that, in some cases, the layers of the solidified melt were "locked" inside the copper plate. This led to the formation of volumes resembling "multilayered sandwiches," in which the intermetallic inclusions were separated by the parent material (copper). ${ }^{[22]}$
The mesoscale analysis based on the energy dispersive $\mathrm{X}$-ray spectrometry in SEM performed in an earlier work $^{[15]}$ clearly indicated that a higher "average" concentration of copper was observed for the intermetallic inclusions situated in the nearest neighborhood of the copper plate and a poorer concentration in the layers situated closer to the aluminum sheet. The above tendency of the chemical composition changes is not so evident for particular intermetallic inclusion. The micro-/nanoscale analyses performed in this work by means of the TEM/EDX technique documented strong differentiation of the chemical composition inside a particular inclusion of the solidified melt. Most of the observed phases were metastable, of the $\mathrm{Cu}_{m} \mathrm{Al}_{n}$ type, with the copper concentration (in pct at.) mostly ranged between 33 and 67 pct. The TEM analysis also revealed three equilibrium phases, i.e., $\gamma-\mathrm{Al}_{4} \mathrm{Cu}_{9}, \eta-\mathrm{AlCu}$, and $\Theta-\mathrm{Al}_{2} \mathrm{Cu}$ type. However, all of them (i.e., equilibrium and metastable phases) were crystalline.

\section{Features close to the Interface - a comparison} with other bonding techniques

The diffusion-controlled processes do not play any decisive role in the intermetallic inclusion formation "in 

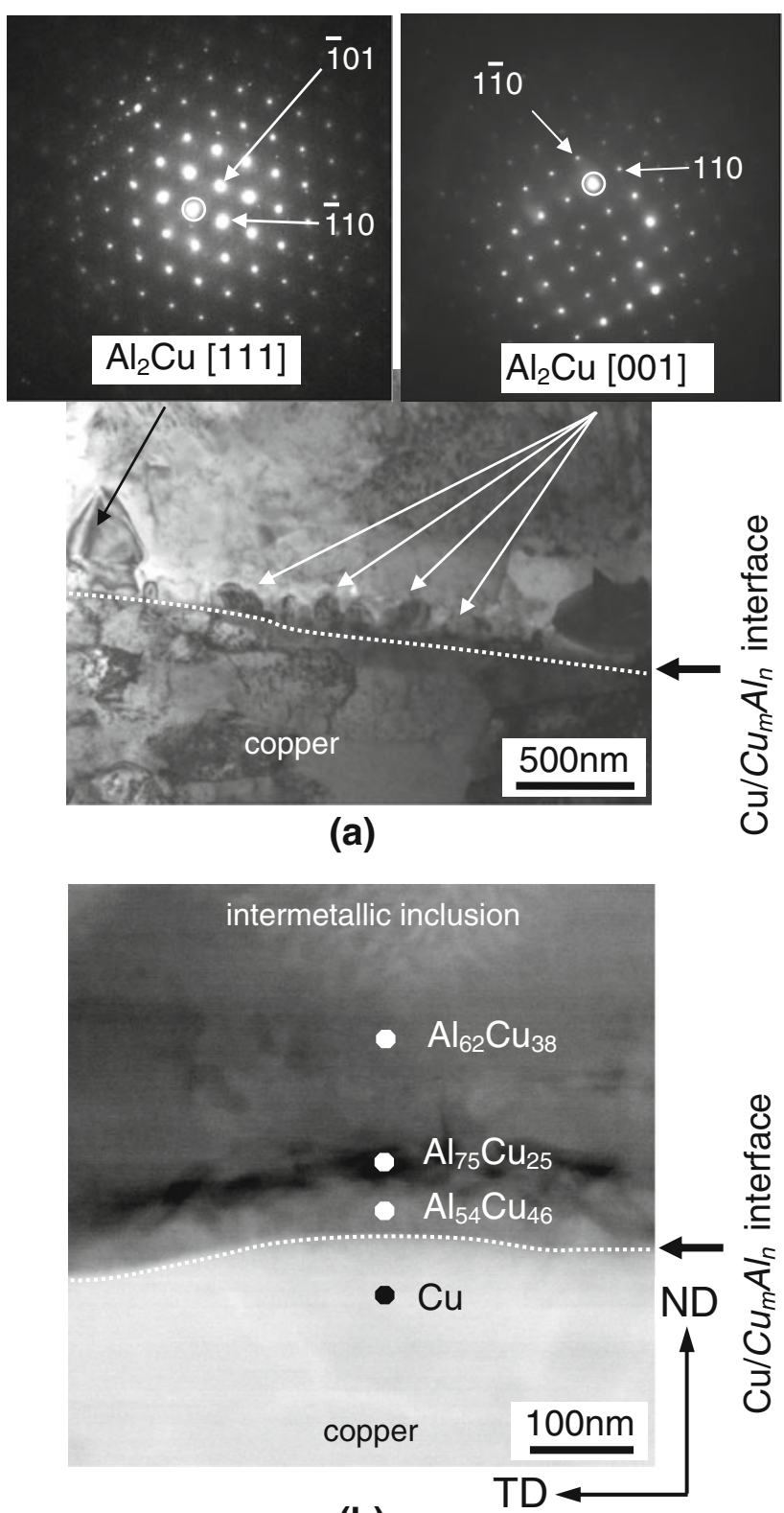

(b)

Fig. 14-Micrographs showing microstructure near the $\mathrm{Cu} / \mathrm{Cu}_{m} \mathrm{Al}_{n}$ boundary. (a) Nanograins of the $\mathrm{CuAl}_{2}$ phase growing inward in the intermetallic zone. TEM bright field imaging and the corresponding SAD patterns. (b) An almost "continuous" intermetallic layer formed at the $\mathrm{Cu} / \mathrm{Cu}_{m} \mathrm{Al}_{n}$ interface.

state" just after bonding. However, the solid-state transformations can be crucial for the growth of the intermetallic phases after aging. In this respect, much of the literature data are related to the composites formed by the cold roll welding process, e.g., ${ }^{[20]}$ diffusion bonding, e.g., ${ }^{[31-33]}$ soldering (wire bonding), e.g., ${ }^{[34-36]}$ or friction stir welding, e.g., ${ }^{[37,38]}$ and then annealing.

As for the $\mathrm{Cu} / \mathrm{Al}$ bonds, most of the previous works have been dedicated to the analyses of the intermetallic compound growth which appears after wire bonding at the wire $(\mathrm{Cu}) / \operatorname{pad}(\mathrm{Al})$ interfaces in (micro)electronic applications, e.g. ${ }^{[34-36]}$ No intermetallics were observed in the as-bonded state. ${ }^{[34]}$ However, after a "sufficiently long time" of high temperature aging, the continuous layers of equilibrium phases (of planar morphology) were formed at the bonded interface, e.g. ${ }^{[31,37]}$ As the aging time increased, these intermetallic phases developed inward, to the central area, and eventually formed a complete layer between the bond and the pad. Similar effects were also observed in other welding techniques, e.g., cladding by rolling, e.g., ${ }^{[20]}$ or friction stir welding, e.g. ${ }^{[38]}$

The growth kinetics of the intermetallic phases, in the conditions close to the equilibrium, is always diffusioncontrolled. This leads to a strictly defined sequence of the equilibrium intermetallic compounds. For example, the interface in the diffusion-bonded $\mathrm{Cu} / \mathrm{Al}$ laminates, after a "long time" of aging, is composed of three intermetallic phases, $\gamma-\mathrm{Al}_{4} \mathrm{Cu}_{9}, \eta-\mathrm{AlCu}$, and $\Theta-\mathrm{Al}_{2} \mathrm{Cu}$, arrayed in the sequence from the $\mathrm{Cu}$ to the $\mathrm{Al}$ plate, e.g. ${ }^{[31]}$ The phases enriched with $\mathrm{Al}$ were formed close to the $\mathrm{Al}$ plate, whereas the phases enriched with $\mathrm{Cu}$ were close to the copper plate. This regularity of the phase distribution, observed in near equilibrium conditions, is completely "alien" for explosive welding clads (in the as-bonded state).

The theoretical predictions of the intermetallic phase formation, in the near equilibrium conditions of the solid-state diffusion processes and within a broad range of temperatures, could be based on the free energy values. Since this free energy was negative (see Table II), the $\mathrm{Al}_{4} \mathrm{Cu}_{9}$ phase was predicted to be formed first at the $\mathrm{Cu}-\mathrm{Al}$ interface and then the $\mathrm{AlCu}$ and the $\mathrm{Al}_{2} \mathrm{Cu}$ phases.

However, the experimental observations show that $\mathrm{Al}_{2} \mathrm{Cu}$ was the first phase in the diffusion-bonded $\mathrm{Cu} / \mathrm{Al}$ laminates, which appeared between $\mathrm{Cu}$ and $\mathrm{Al}$ - before $\mathrm{Al}_{4} \mathrm{Cu}_{9}$ and $\mathrm{AlCu}$ as observed in. ${ }^{[31,32,35]}$ The differences in the solubility of the elements in the solid solution and the melting temperatures [933 K $\left(660{ }^{\circ} \mathrm{C}\right)$ for $\mathrm{Al}$ and $1356 \mathrm{~K}\left(1083{ }^{\circ} \mathrm{C}\right)$ for $\mathrm{Cu}$ ] can be the reason why the $\mathrm{Al}_{2} \mathrm{Cu}$ phase is more frequently observed in the solidified melt than the other equilibrium phases. Guo et al. ${ }^{[31]}$ and Chen et al. ${ }^{[35]}$ studied the thermodynamic aspects of the growth of the $\mathrm{Al}-\mathrm{Cu}$ intermetallic compounds close to the interface after the $\mathrm{Cu}$ wire bonding. On the basis of the different solubility of either element, they stated that since the solubility limit of $\mathrm{Cu}$ in $\mathrm{Al}$ is an order of magnitude less than that of $\mathrm{Al}$ in $\mathrm{Cu}$, the $\mathrm{Al}(\mathrm{Cu})$ solid solution would be expected to saturate first, resulting in the preferred nucleation of $\mathrm{Al}_{2} \mathrm{Cu}$.

In the period of temperature increase in explosive welding, the Al crystals melted first and solidified later than copper. Because of this, larger volumes of the Al plate (with respect to $\mathrm{Cu}$ ) were melted and the liquid which was enriched with the $\mathrm{Al}$ and $\mathrm{Al}_{2} \mathrm{Cu}$ phase was detected more frequently. (The formation of $\mathrm{Al}_{2} \mathrm{Cu}$ requires more than double amount of the $\mathrm{Al}$ needed for the formation of $\mathrm{AlCu}$ and more than four times the amount of the $\mathrm{Al}$ needed for $\mathrm{Al}_{4} \mathrm{Cu}_{9}$, for the same amount of the consumed $\mathrm{Cu}$.) 
Table II. Selected Characteristics of Copper Intermetallic Compounds ${ }^{[34]}$ and the Corresponding Formation Energy of the Cu-Al Intermetallic Phases According to Ref. [31]

\begin{tabular}{lclc}
\hline Phase & $\begin{array}{c}\text { Cu Concentration } \\
\text { (at. pct) }\end{array}$ & $\begin{array}{c}\text { Crystallographic } \\
\text { Structure }\end{array}$ & $\begin{array}{c}\text { Formation Energy } \\
\Delta H_{\mathrm{f}}(\mathrm{kJ} / \mathrm{mol})\end{array}$ \\
\hline $\mathrm{Al}$ & $0-2.84$ & cubic & - \\
$\mathrm{CuAl}$ & $*$ & tetragonal & $-13.05(-15.036)$ \\
$\mathrm{CuAl}^{*}$ & $31.9-33.0$ & monoclinic & $-19.92(-20.656)$ \\
$\mathrm{Cu}_{4} \mathrm{Al}_{3}$ & $49.8-52.3$ & monoclinic & -20.40 \\
$\mathrm{Cu}_{3} \mathrm{Al}_{2}$ & $55.2-56.3$ & trigonal & -20.67 \\
$\mathrm{Cu}_{9} \mathrm{Al}_{4}{ }_{\mathrm{Cu}}$ & $59.3-61.9$ & cubic & $-21.69(-20.466)$ \\
$\mathrm{Cu}$ & $62.5-69.0$ & cubic & - \\
\hline
\end{tabular}

The numbers in the parentheses were reported by Chen et al. ${ }^{[35]}$ The $(*)$ marked phases were detected in this work inside the intermetallic inclusion.

\section{SUMMARY}

The cladding of $\mathrm{Cu}$ onto $\mathrm{Al}$ was accomplished by means of explosive welding. Particular attention was paid to the analysis of the changes which were observed in the intermediate layers. The following detailed conclusions can be drawn.

- The macroscale characterizations of the interface revealed flat and wavy forms, with the rarely observed intermetallic inclusions. The discrete elongated regions occupied by the intermetallic inclusions occurred preferentially at the crests or within the vortex of the waves. The thickness of this solidified melt layers near the bonding interface was ranged between "a few" and about 10 microns.

- Local melting leads to the formation of intermetallics of different types. While three crystalline, equilibrium phases - $\gamma-\mathrm{Al}_{4} \mathrm{Cu}_{9}, \eta-\mathrm{AlCu}$, and $\Theta-\mathrm{Al}_{2} \mathrm{Cu}$-were identified inside the solidified melt, the last one was dominant. The equilibrium phases formed nearly equiaxed grains and were always surrounded by metastable intermetallic phases (also crystalline) in the form of dendrites of different chemical compositions. Moreover, no significant regularity in the phase distribution (inside intermetallic inclusions) with respect to the parent sheets was observed. The latter facts univocally show the dominance of the processes occurring in the rapidly crystallized liquid.

- Close to the $\mathrm{Cu} / \mathrm{Cu}_{m} \mathrm{Al}_{n}$ interface, a structure of fine grains (mostly of the $\mathrm{Al}_{2} \mathrm{Cu}$ type) growing inside the intermetallic layer was observed. The $\mathrm{Al} / \mathrm{Cu}_{m} \mathrm{Al}_{n}$ interface was very sharp and free of fine grains.

- During the bond formation, the layers of parent sheets near the interfaces underwent intense plastic deformation. Consequently, deformation microstructure features, i.e., structure refinement, equiaxed or elongated dislocation cells, slip bands, and (micro)twins (in copper plate) were observed. The structure of elongated cells was typically observed in the $\mathrm{Al}$ sheet close to the interface. The microstructure of the $\mathrm{Cu}$ sheet was composed of fine, nearly equiaxed grains. Their internal microstructure was composed of non-regular dislocation arrangements. (Micro)twins were found on the $\mathrm{Cu}$ side close to the $\mathrm{Cu} / \mathrm{Al}$ interface.

- The Vickers microhardness in the parent materials increased significantly as the interface was approached. However, in the areas adhering to the interface, a strong decrease of microhardness was observed. The microhardness values inside the areas of solidified melt very often reached $700 \mathrm{HV}$. They were several times higher than those observed in the $\mathrm{Cu}$ or $\mathrm{Al}$ close to the interface.

\section{ACKNOWLEDGMENTS}

The authors give thanks to Mr. Z. Szulc and High Energy Technologies Works "Explomet" (Opole, Poland) for the provision of the $\mathrm{Cu} / \mathrm{Al}$ clad. The authors are also grateful to Dr J. Wojewoda-Budka (IMIM PAN in Krakow) for the thin foils' preparation by FIB. This work was supported in part by the Polish Ministry of Science and Higher Education, projects no UMO-2012/04/M/ST8/00401 and UMO-2012/05/B/ ST8/02522.

\section{OPEN ACCESS}

This article is distributed under the terms of the Creative Commons Attribution License which permits any use, distribution, and reproduction in any medium, provided the original author(s) and the source are credited.

\section{REFERENCES}

1. B. Crossland: Explosive Welding of Metals and its Application, Oxford University Press, London, 1981

2. T.Z. Blazynski: Explosive Welding, Forming and Compaction, Applied Science Publishers LTD, New York, 1983.

3. F. Findik: Mater. Des., 2011, vol. 32, pp. 1081-93.

4. S.A.A. Akbari Mousavi, S.T.S. Al-Hassani, and A.G. Atkins: Mater. Des., 2008, vol. 29, pp. 1334-52.

5. S.H. Carpenter: in Shock Waves and High-Strain-Rate Phenomena in Metals, M.A. Meyers and L.E. Murr, eds., Plenum Press, New York, 1981, pp. 941-59. 
6. D.G. Brasher, D.J. Butler, and A.W. Hare: in Shock Waves for Industrial Applications, L.E. Murr, ed., Noyes Publications, 1988, pp. 216-36.

7. N.V. Naumovich, A.I. Yadevich, and N.M. Chigrinova:, in Shock Waves for Industrial Applications, L.E. Murr, ed., Noyes Publications, USA, 1988, pp. 170-215.

8. J. Song, A. Kostka, M. Veehmayer, and D. Raabe: Mater. Sci. Eng., 2011, vol. A528, pp. 2641-47.

9. A.G. Mamalis, A. Szalay, N.M. Vaxevanidis, and D.I. Pantelis: Mater. Sci. Eng., 1994, vol. A188, pp. 267-75.

10. M. Gerland, H.N. Presles, J.P. Guin, and D. Bertheau: Mater. Sci. Eng., 2000, vol. A280, pp. 311-19.

11. Y. Yang, B. Wang, and J. Xiong: J. Mater. Sci., 2006, vol. 41, pp. 3501-05.

12. S.A.A. Akbari Mousavi and P. Farhadi Sartangi: Mater. Des., 2009, vol. 30, pp. 459-68.

13. K. Hokamoto, K. Nakata, A. Mori, S. Ii, R. Tomoshige, S. Tsuda T. Tsumura, and A. Inoue: J. Alloys Compd., 2009, vol. 485, pp. 817-21.

14. S.A.L. Salem and S.T.S. Al-Hassani:, in Shock Waves and HighStrain-Rate Phenomena in Metals, M.A. Meyers and L.E. Murr, eds., Plenum Press, New York, 1981, pp. 1003-18.

15. H. Paul, M. Faryna, M. Prażmowski, and R. Bański: Arch. Metall. Mater., 2011, vol. 56, pp. 463-74.

16. Y. Zhang, S.S. Babu, C. Prothe, M. Blakely, J. Kwasegroch, M. LaHa, and G.S. Daehn: J. Mater. Process. Technol., 2011, vol. 211 , pp. $944-52$.

17. K.F. Kelton and A.L. Greer: Non-Cryst. Solids, 1986, vol. 79, pp. 295-309.

18. W. Kurtz and D.J. Fisher: Fundamentals of Solidification, Fourth Revised Edition ed., Trans Tech Publications LTD, Switzerland, 1998, pp. 133-55.

19. H. Paul: unpublished research.

20. M. Abbasi, A. Karim Taheri, and M.T. Salehi: J. Alloys Compd., 2001, vol. 319, pp. 233-41.
21. Y. Ishii, T. Onzawa, and T. Oinuma: J. Jpn. Weld. Soc., 1969, vol. 38, pp. 1372-78 (in Japanese).

22. H. Paul, M. Miszczyk, M. Prażmowski, Z. Szulc: Inżynieria Materiaowa, 2010, vol. 5, pp. 1339-46 (in Polish).

23. H. Paul, M. Miszczyk, and M. Prażmowski: Mater. Sci. Forum, 2012, vols. 702-703, pp. 603-06.

24. K. Ken, S. Keinji, I. Keinji, M. Keinji, and K. Hidenori: J. Light Metall. Weld Construct., 2002, vol. 40, pp. 403-10.

25. N. Kahraman, B. Gülenç, and F. Findik: J. Mater. Proc. Technol., 2005, vol. 169, pp. 127-33.

26. B. Gülenç: Mater. Des., 2008, vol. 29, pp. 275-78.

27. M. Hammerschnidt and H. Kreye:, Shock Waves and High-StrainRate Phenomena in Metals, M.A. Meyers and L.E. Murr, eds., Plenum Press, New York, 1981, pp. 961-73.

28. L.F. Trueb: J. Appl. Phys., 1969, vol. 40, pp. 2976-87.

29. K.D. Leedy and J.F. Stubbins: Mater. Sci. Eng., 2001, vol. A297, pp. $10-18$.

30. G. Martin: Phys. Rev. B, 1984, vol. 30, pp. 1424-33.

31. Y. Guo, G. Liu, H. Jin, Z. Shi, and G. Qiao: J. Mater. Sci., 2011, vol. 46, pp. 2467-73.

32. Y. Tanaka, M. Kajihara, and Y. Watanabe: Mater. Sci. Eng., 2007, vols. A445-A446, pp. 355-63.

33. H. Assadi, A.A. Shirzadi, and E.R. Wallach: Acta Mater., 2001, vol. 49, pp. 31-39.

34. C.J. Hang, C.Q. Wang, M. Mayer, Y.H. Tian, Y. Zhou, and H.H. Wang: Microelectron. Reliab., 2008, vol. 48, pp. 416-24.

35. J. Chen, Y.-S. Lai, Y.-W. Wang, and C.R. Kao: Microelectron. Reliab., 2011, vol. 51, pp. 125-29.

36. C. Xia, Y. Li, U.A. Puchkov, S.A. Gerasimov, and J. Wang: Vacuum, 2008, vol. 82, pp. 799-804.

37. W.-B. Lee, K.-S. Bang, and S.-B. Jung: J. Alloy. Compd., 2005, vol. 390, pp. 212-19.

38. C. Genevois, M. Girard, B. Huneau, X. Sauvage, and G. Racineux: Metall. Mater. Trans. A, 2011, vol. 42A, pp. 2290-95. 